\title{
Ensino de inteligência competitiva no apoio à busca do sucesso profissional de graduandos em biblioteconomia e ciência da informação
}

\author{
Leonardo Guimarães Garcia ${ }^{I}$ \\ http://orcid.org/0000-0002-9195-0567 \\ I Universidade de São Paulo, SP, Brasil. \\ Docente do curso de Biblioteconomia e Ciência Informação.
}

http://dx.doi.org/10.1590/1981-5344/4233

A crescente complexidade da nossa realidade informacional demanda profissionais da informação dotados de diversas competências, várias das quais coincidentes com aquelas necessárias ao exercício da Inteligência Competitiva (IC). Uma vez que tais competências se baseiam em atributos de competência (conhecimentos, habilidades e atitudes - CHA), o desenvolvimento desses atributos garante as bases para várias das competências necessárias ao moderno profissional da informação. Sendo assim, o presente trabalho analisa os resultados de um processo de ensino em IC baseado em metodologias ativas, no que diz respeito ao aprendizado dos alunos em diferentes atributos de competência e à importância dos mesmos para o sucesso profissional idealizado pelos estudantes. Quanto à metodologia, essa pesquisa é exploratória e tem como método a Pesquisa-Ação. Os resultados indicam: 1) o bom desempenho do processo de ensino quanto ao aprendizado dos atributos de competência; 2) que os atributos trabalhados possuem, na opinião dos próprios alunos, grande importância para o alcance do sucesso 
profissional que almejam. Como conclusão, acredita-se haver no processo de ensino descrito muitos componentes passíveis de serem replicados em outros cursos de Biblioteconomia e Ciência da Informação para a geração de níveis similares de ganho de aprendizado e alavancagem do sucesso profissional dos nossos egressos.

Palavras-Chave: Inteligência competitiva; ensino; metodologias ativas; sucesso profissional; Biblioteconomia e Ciência da Informação.

\section{Competitive intelligence teaching to support the pursuit of professional success of library and information science students}

The increasing complexity of our informational reality demands information professionals with diverse competences, several of which coincide with those required for the exercise of Competitive Intelligence (CI). Since such competences are based on competence attributes (Knowledge, Skills and Attitudes - KSA), the development of these attributes provides the basis for many of the competences needed by the modern information professional. Thus, the present work analyzes the results of a teaching process in CI based on active methodologies, regarding the students' learning in different competence attributes and their importance for the professional success idealized by the students. As for the methodology, this research is exploratory and its method is Action Research. The results indicate: 1) the good performance of the teaching process regarding the learning of competence attributes; 2) that the attributes worked have, in the opinion of the students themselves, great importance for the achievement of the professional success they aim for. In conclusion, it is believed that there are in the teaching process described many components that can be replicated in other Bachelors of 
Library and Information Science to generate similar levels of learning gain and leverage the professional success of our graduates.

Keywords: Competitive Intelligence; Teaching; Active Methodologies; Professional success; Library and Information Science

Recebido em 20.12.2019 Aceito em 28.05.2020

\section{Introdução}

A crescente complexidade da nossa realidade informacional demanda profissionais da informação dotados de diversas competências técnicas e comportamentais (FARIA et al., 2005).Flexibilidade, visão holística,boa amplitude de conhecimentos (GUIMARÃES, 1997) e o traquejo com as novas tecnologias e metodologias de uso da informação (VALENTIM, 2000)se somam às competências informacionais para a coleta, análise e disseminação (FERREIRA, 2003), de modo a garantir profissionais da informação capazes de se encaixar em perfis profissionais cada vez mais exigentes (ARRUDA; MARTELETO; SOUZA, 2000), num mercado de trabalho altamente competitivo, dinâmico e tecnológico (DUTRA; CARVALHO, 2006).

Várias dessas competências coincidem com aquelas necessárias ao exercício bem-sucedido da Inteligência Competitiva (IC), aqui compreendida como um serviço informacional (e, portanto, passível de ser praticado por profissionais da informação) com foco na produção de informação de alto valor agregado para a tomada de decisão (FULD, 1995). Devido a essa conexão, pode-se supor que o ensino de IC possa ser uma maneira de desenvolver competências capazes de conduzir os profissionais da informação ao sucesso profissional.

Por outro lado, como mostra Oliveira e Lacerda (2007) e Amaral et al. (2008), as competências em IC podem ser descritas por meio de atributos de competência (conhecimentos, habilidades e atitudes - CHA). Esse expediente é bem conveniente ao ensino, uma vez que deixa claro os diferentes níveis e objetivos educacionais a serem alcançados, bem como facilita o desenho do processo educacional e de suas práticas. Diante essa perspectiva, o ensino efetivo em IC deveria ser projetado para atuar nas três dimensões do CHA, não focando apenas nos conhecimentos.Ao integrar teoria e prática por meio de metodologias ativas, um processo de ensino em IC para alunos dos cursos de Biblioteconomia e Ciência da 
Informação poderia suprir essa ambição do desenvolvimento integral do CHA.

Dada a possibilidade do ensino de IC ser mobilizado como auxílio ao sucesso profissional de nossos alunos, ocorreu-nos que o CHA a ser formado também deveria dialogar com a visão de cada um deles sobre o que é o sucesso profissional para si. Nossa obrigação como educadores não se esgota em ampliar a empregabilidade dos nossos futuros egressos, tendo como foco unicamente as demandas do mercado de trabalho. Devemos igualmente ser capazes de propor a eles processos formativos cujo CHA resultante represente, a seus olhos, uma solução para o alcance do sucesso que eles próprios desejam. Em suma, o processo de formação ideal nesse contexto deveria suprir demandas de CHA provenientes: 1) da IC; 2) do mercado de trabalho; 3) da concepção de sucesso profissional dos próprios alunos.

Sendo assim, o objetivo desse trabalho é propor um processo de ensino em IC direcionado a graduandos de Biblioteconomia e Ciência da Informação, bem como analisar seus resultados no que diz respeito tanto ao aprendizado de diferentes atributos de competência quanto à conexão dos mesmos à ideia de sucesso profissional dos alunos.

A seguir, é apresentada a metodologia utilizada no desenvolvimento desse trabalho. Após isso, são apresentadas as referências centrais do processo de ensino(cujo escopo são as metodologias ativas), bem como o processo de ensino em si, descrito brevemente em seus aspectos primordiais. Os resultados do processo em termos da ampliação do $\mathrm{CHA}$ e de sua ligação à imagem de sucesso profissional dos alunos são, na sequência, apresentados. Por fim, as considerações finais discutem a contribuição do trabalho.

\section{Inteligência Competitiva e o seu ensino}

Como dito anteriormente, a IC pode ser vista como um serviço cujo foco é a produção de informação de alto valor agregado para a tomada de decisão sobre o mercado e sobre os concorrentes (FULD, 1995). Essa visão é convergente com aquela presente em Tyson (2010), para o qual a IC é um processo sistemático que almeja gerar conhecimento estratégico sobre os aspectos internos e externos essenciais do mercado de atuação da organização, incluindo a competição atual e futura a qual a mesma está/estará sujeita. Tal conhecimento se converte em vantagem para a organização quando a direciona à melhor decisão (TYSON, 2010).

Para Queyras e Quoniam (2006), a IC é consequência da passagem da era industrial para a era da informação, passagem esta suportada por uma contundente evolução das Tecnologias da Informação e Comunicação (TICs). Nesse novo contexto, a informação e o conhecimento tornam-se 
os ativos mais essenciais à produção sustentável de riquezas, ao invés dos meios de produção característicos da era industrial.

Vários autores da área destacam que o uso da informação para a tomada de decisão ocorre desde a Antiguidade. Essa menção normalmente tem o objetivo de distinguir as informações não tratadas ou analisadas daquelas de alto valor para o decisor (a qual muitos chamam "inteligência acionável" ou simplesmente "inteligência"). O objetivo da IC é justamente viabilizar a produção dessa informação de alto valor (KAHANER, 1996).

A IC se consolidou principalmente a partir da década de 1970, com a sua inserção em grandes organizações multinacionais (tais como a IBM e a Motorola) (TARAPANOFF, 2006). Desde então os métodos vem sendo aperfeiçoados e as unidades de inteligência vêm evoluindo rumo à sua maturidade (GARCIA, 2013), num processo de institucionalização abrangente que abarca diferentes fenômenos, desde o estabelecimento da área como uma disciplina acadêmica (MARCIAL, 2016) até a consolidação das suas profissões e do seu ensino nas universidades.

Apesar disso, a oferta de ensino universitário em IC ainda é limitada. Parte dessa demanda tem sido suprida por associações como a SCIP(Strategic \& Competitive Intelligence Professionals https://www.scip.org/), que desempenha há décadas um papel central na formação dos profissionais de IC, seja através de cursos, seminários ou mesmo publicações sobre o assunto (tais como CALOF, 1999; GILAD, 2003; GUTOWSKI, 2007; McGONAGLE, 2007), ou por instituições de ensino especializadas em IC tais como a Academy of Competitive Intelligence (https://academyci.com/), organização norte-americana que em mais de trinta anos já capacitou mais de 10.000 profissionais e tomadores de decisão de mais de 70 países. A literatura traz ainda relatos do envolvimento de governos com o esforço de treinamento em IC (RUNTUWENE; KENAP; PALILINGAN, 2014; CALOF, 2016).

No que diz respeito às universidades, o ensino de CI vem criando soluções próprias, como por exemplo a combinação de aulas com atividades práticas (MILLER, 1994; BEXON et al., 2002; GILAD, 2003; FLEISHER, 2004; LEMMER, 2015). A literatura também destaca o uso de projetos como em Blenkhorn e Fleisher (2003), que apontam o quanto os mesmos são apreciados por alunos de graduação que, por meio deles, podem confrontar seus conhecimentos com o mundo real. Uma outra vantagem dos projetos é que sua realização provoca os alunos a superarem suas limitações, tais como o desconhecimento da terminologia da área de negócios ou a dificuldade de raciocínio lógico-dedutivo (GUTOWSKI, 2007).

Outra constante na literatura sobre o ensino de IC são as competências. Esse é um assunto em desenvolvimento e, por esse 
motivo, tem suscitado diversos debates ao longo dos anos com pouco consenso quanto às definições e abordagens. Aqui, adotamos a definição de Amaral et. al. (2011), uma vez que a mesma foi consolidada num estudo direcionado à IC:

Competência pode ser compreendida como aquilo que qualifica a pessoa apta a realizar, no presente momento, sua atividade com maestria, tendo para tanto suficientes conhecimentos, habilidades e atitudes (AMARAL et al., 2011, p. 127).

Essa definição é condizente com a visão de Zarifian (2001), para o qual, as competências resultam da combinação indissociável de Conhecimentos (que representa o que o indivíduo sabe e pode mobilizar a fim de compreender a realidade na qual vive e opera), Habilidades (i.e., aquilo que o indivíduo sabe fazer e pode utilizar para alcançar seus objetivos) e Atitudes (responsáveis pela ética, motivação e outros elementos comportamentais indispensáveis à atuação bem sucedida). Essas três dimensões representam os atributos de competência (ou CHA sigla resultante da união das letras iniciais das três dimensões). No esteio dessa perspectiva, vários trabalhos têm sido desenvolvidos. Destaca-se o estudo de Amaral et al. (2008), que apresenta um modelo de mapeamento do CHA de profissionais de IC, uma base de referência desses atributos e um glossário desses termos.

Em suma, vê-se que as competências em IC podem ser descritas por meio de atributos de competência (ou CHA) e que essa representação está amparada por uma ampla literatura (por exemplo: CALOF, 1999; KALB, 2003; OLIVEIRA; LACERDA, 2007; AMARAL et al., 2008; ZHOU; WANG, 2013), a qual representa a convicção de muitos educadores de que o ensino efetivo de IC deve impactar as competências e os seus atributos.

\section{Metodologias ativas e o processo de ensino adotado}

Tradicionalmente, os processos de ensino dedicam-se preponderantemente à transmissão de conhecimentos, e pouco ao desenvolvimento de habilidades e atitudes. Essa abordagem conteudista está fortemente alicerçada em nossa sociedade e, também por esse motivo, transborda para as nossas universidades.

Um caminho para vencermos essa tendência e trabalharmos as três dimensões do CHA simultaneamente é lançar mão de práticas que integrem teoria e prática (GREINER; BHAMBRI; CUMMINGS, 2003), de modo a viabilizar o aprendizado teórico, técnico e comportamental.Essa abordagem coaduna-se à perspectiva das metodologias ativas, baseadas justamente no aprendizado por meio da resolução de problemas práticos, 
num processo em que os alunos são corresponsáveis por sua aprendizagem (RICHARTZ, 2015). Além disso, as metodologias ativas, aplicadas inclusive na formação de profissionais da informação (SODERDAHL, 2011; GARCIA, 2011), ampliam a qualidade do aprendizado (LINTON et al., 2014) e se adaptam a diferentes contextos de formação na graduação centradas nos estudantes (RUIZ-PRIMO et al., 2011).

Ao longo dos últimos nove anos, vêm sendo desenvolvidas e ministradas disciplinas optativas exclusivamente dedicadas ao ensino de IC, baseadas justamente em metodologias ativas e direcionadas a alunos de graduação de um curso de Biblioteconomia e Ciência da Informação. Ambas possuem 4 créditos-aula e 2 créditos-trabalho, e são oferecidas sequencialmente no quinto e sexto períodos da graduação.

O conteúdo programático das disciplinas cobre os aspectos fundamentais da IC (definição e princípios, o Ciclo de IC e seus constituintes e as técnicas de IC mais consagradas - SWOT, as cinco forças de Porter, monitoramento e análise macroambiental). A esse conteúdo-base foram agregados, após a pesquisa bibliográfica e a seleção do CHA, uma série de conteúdos e atividades complementares com 0 intuito de viabilizar o desenvolvimento de habilidades e atitudes por meio da prática, em estágio piloto, da IC em situações reais de aplicação (ao iniciar a primeira disciplina, cada aluno seleciona e obtém autorização de uma organização para aplicar as técnicas de IC na prática - normalmente em seu emprego ou local de estágio, mas também em ONGs ou em empresas-parceiras).

Os tópicos a seguir representam os aspectos essenciais da primeira das duas disciplinas, tal como a mesma é ministrada atualmente após a sua reformulação:

- Realização de atividades diagnósticas sobre a organização estudada pelo aluno;

-Análise da estratégia formal da organização versus sua estratégia informal;

- Realização de projetos-piloto de IC para análise do macroambiente e do ambiente competitivo da organização, tendo como referenciais teóricos as Cinco Forças de Porter e a Análise STEEP (abordagem descrita em Bensoussan e Fleisher (2003) para o estudo das dimensões social, tecnológica, econômica, ecológica e político/legal do macroambiente);

- Realização de várias das atividades dos projetos-piloto (sobretudo as de análise de informações) em sala de aula, com o apoio direto do professor;

- Apresentações curtas, para disseminação dos resultados dos projetos-piloto ao estilo Pecha Kucha (https://www.pechakucha.com/); 
- Redução das aulas expositivas frente aos momentos de discussão dos resultados obtidos por cada aluno nas diversas etapas de realização dos projetos-piloto.

Considerando a demanda latente por parte dos alunos em compreender o real significado do sucesso profissional para si, bem como a necessidade de se estabelecer uma referência para que os mesmos pudessem avaliar o GI de forma menos subjetiva, decidiu-se introduzir no processo de formação em IC o apoio à busca do sucesso profissional pelos alunos. Nesse sentido, a disciplina incorporou conteúdos, debates e atividades específicos, voltados à descoberta do real significado do sucesso profissional, bem como do modo de alcançá-lo.

O objetivo das ações relacionadas ao sucesso profissional foi a criação da estratégia de carreira de cada aluno. A segunda aula da disciplina foi dedicada a explicar a relevância dessa estratégia para a vida de cada um, bem como o modo como ela seria construída ao longo do semestre letivo. Os tópicos constituintes da estratégia de carreira foram os seguintes:

- Seu propósito de carreira: cada aluno deveria descrever a essência do sucesso profissional que almejava para si, bem como os objetivos de curto prazo para a realização desse sucesso;

- Seus pontos fortes e fracos: inventário pessoal sobre as forças e fraquezas individuais mais determinantes para o alcance do sucesso almejado;

- Suas oportunidades e ameaças: lista das contingências externas favoráveis e desfavoráveis mais influentes sobre a realização do sucesso profissional desejado;

- Sua estratégia de carreira: representação textual ou esquemática (como um mapa mental, por exemplo) do caminho para a realização do sucesso almejado.

O sentido e a importância de cada tópico foram discutidos na segunda aula, assim como a orientação geral para a sua realização. A fim de facilitar a compreensão dos tópicos, os mesmos foram convertidos em perguntas e explicados aos alunos com o auxílio do Quadro 1.

Quadro 1: Elementos constituintes da estratégia de carreira dos alunos.

\begin{tabular}{|c|l|}
\hline \multicolumn{2}{|c|}{ SEU PROPÓSITO DE CARREIRA } \\
\hline Perguntas & Esclarecimentos sobre o significado e/ou o modo de respondê- \\
las
\end{tabular}




\begin{tabular}{|c|c|}
\hline concretize? & representada na resposta à pergunta "1" \\
\hline & SEUS PONTOS FORTES E FRACOS \\
\hline Perguntas & $\begin{array}{l}\text { Esclarecimentos sobre o significado e/ou o modo de respondê- } \\
\text { las }\end{array}$ \\
\hline $\begin{array}{l}\text { 3. Quais são seus principais } \\
\text { pontos fortes (i.e., seus aspectos } \\
\text { internos que mais favorecem o } \\
\text { alcance do seu sucesso } \\
\text { profissional almejado)? }\end{array}$ & $\begin{array}{l}\text { Considere o universo de suas qualidades profissionais (domínio de } \\
\text { conhecimentos técnicos, habilidades, atitudes, competências e } \\
\text { motivação para o trabalho e/ou para o seu próprio } \\
\text { desenvolvimento) e, na sequência, selecione seus pontos fortes } \\
\text { mais confiáveis e mais relevantes frente às respostas das } \\
\text { perguntas " } 1 \text { " e " } 2 \text { ". Indique em torno de } 5 \text { itens. } \\
\text { Dê preferência a pontos fortes já manifestos em situações } \\
\text { profissionais reais, e àqueles indicados por chefes e colegas de } \\
\text { trabalho confiáveis. }\end{array}$ \\
\hline $\begin{array}{l}\text { 4. Quais são seus principais } \\
\text { pontos fracos (i.e., seus aspectos } \\
\text { internos que mais atrapal ham o } \\
\text { alcance do seu sucesso } \\
\text { profissional almejado)? }\end{array}$ & $\begin{array}{l}\text { Considere o universo de suas dificuldades profissionais (falta ou } \\
\text { deficiência quanto a conhecimentos técnicos, habilidades, } \\
\text { atitudes, competências e motivação para o trabalho e/ou para o } \\
\text { seu próprio desenvolvimento) e, na sequência, selecione seus } \\
\text { pontos fracos mais confiáveis e mais relevantes frente às } \\
\text { respostas de " } 1 \text { " e " } 2 \text { ". Indique em tomo de } 5 \text { itens. } \\
\text { Dê preferência a pontos fracos já manifestos em situações } \\
\text { profissionais reais, e àqueles indicados por chefes e colegas de } \\
\text { trabalho confiáveis. }\end{array}$ \\
\hline \multicolumn{2}{|r|}{ SUAS OPORTUNIDADES E AMEAÇAS } \\
\hline Perguntas & $\begin{array}{l}\text { Esclarecimentos sobre o significado e/ou o modo de respondê- } \\
\text { las }\end{array}$ \\
\hline $\begin{array}{l}\text { 5. Quais as principais } \\
\text { oportunidades disponíveis (i.e., } \\
\text { que aspectos extemos a você } \\
\text { mais favorecem o alcance do seu } \\
\text { sucesso profissional almejado)? }\end{array}$ & $\begin{array}{l}\text { Considere o universo de elementos externos a você capazes de } \\
\text { favorecer a materialização do seu sucesso profissional almejado } \\
\text { (ex.: momento favorável da sua organização - caso esteja } \\
\text { trabalhando- ou do setor em que ela atua - ou que você deseja } \\
\text { atuar, feedbacks positivos por parte da sua organização quanto à } \\
\text { sua carreira e suas possibilidades de crescimento e } \\
\text { desenvolvimento, obtenção de diplomas ou certificações, ofertas } \\
\text { de vagas de emprego na sua área de interesse, intercâmbio, etc.). } \\
\text { Na sequência, selecione as oportunidades mais confiáveis e mais } \\
\text { relevantes frente às respostas de " } 1 \text { " e " } 2 \text { ". Indique em torno de } 5 \\
\text { itens. }\end{array}$ \\
\hline $\begin{array}{l}\text { 6. Quais as principais ameaças } \\
\text { existentes (i.e., que aspectos } \\
\text { externos a você mais atrapalham } \\
\text { o alcance do seu sucesso } \\
\text { profissional almejado)? }\end{array}$ & $\begin{array}{l}\text { Considere o universo de elementos, dentro e fora da sua atual } \\
\text { organização, capazes de atrapalhar a materialização do seu } \\
\text { sucesso profissional almejado (ex.: momento desfavorável da sua } \\
\text { organização - caso esteja trabalhando- ou do setor em que ela } \\
\text { atua-ou que você deseja atuar, indicações ou feedback negativos } \\
\text { por parte da sua organização quanto à sua carreira, crise } \\
\text { econômica, poucas ofertas de vagas na sua área de interesse, }\end{array}$ \\
\hline
\end{tabular}




\begin{tabular}{|c|l|}
\hline & $\begin{array}{l}\text { etc.). Na sequência, selecione as ameaças mais evidentes e mais } \\
\text { impactantes frente às respostas de "1" e "2". Indique em torno } \\
\text { de5 } \text { itens. }\end{array}$ \\
\hline SUA ESTRATÉGIA DE CARREIRA \\
\hline Pergunta & $\begin{array}{l}\text { Esclarecimentos sobre o significado e/ou o modo de respondê- } \\
\text { las }\end{array}$ \\
\hline $\begin{array}{c}\text { 7. Qual é a sua estratégia } \\
\text { profissional? }\end{array}$ & $\begin{array}{l}\text { Represente, na forma de texto e/ou mapa mental o caminho que } \\
\text { você acredita ser o mais viável e produtivo para realizar sua visão } \\
\text { de sucesso presente na resposta de "1". }\end{array}$ \\
\hline
\end{tabular}

Fonte: Da pesquisa.

Ainda na segunda aula foi explicado aos alunos que a construção da estratégia profissional individual iria ocorrer ao longo de todo o semestre letivo, e que o documento final da estratégia só seria entregue na última aula. Além disso, foi apresentada a eles a proposta estruturada de debates denominada "Roteiro para o Sucesso", idealizada para orientar e auxiliar a construção da estratégia profissional de cada um. Essa agenda seria implementada em parte em sala de aula (30 minutos semanais), e em parte através do grupo privado criado no Facebook justamente com esse propósito. Desse modo, os alunos entenderam que a estratégia a ser construída seria fruto de uma longa e aprofundada reflexão individual, mediada pelas discussões e orientações em sala e no Facebook. As atividades do "Roteiro para o Sucesso", bem como seus resultados, são apresentados na seção 5.1 .

Após ministrar a primeira disciplina optativa com essa abordagem, a mesma foi avaliada pelos alunos utilizando um questionário. De maneira anônima, os seis alunos matriculados na disciplina responderam perguntas sobre 0 GA e 0 GI frente aos diferentes atributos de competência adotados. Esses resultados são apresentados nas seções 5.2 e 5.3.

\section{Materiais e métodos}

O desenvolvimento da pesquisa se deu conforme a Figura 1. Após a realização de pesquisa bibliográfica sobre os assuntos correlatos à pesquisa, foram escolhidos atributos de competência ( $\mathrm{CHA}$ ) mais adequados às demandas tanto do processo de ensino de IC (uma disciplina semestral optativa já ministrada há 9 anos, com 4 créditos-aula e 2 créditos-trabalho)quanto do mercado de trabalho.

$\mathrm{Na}$ sequência, a disciplina foi ajustada para comportar o CHA selecionado e então ministrada,tendo seus resultados avaliados sob a ótica tanto do aprendizado dos alunos no CHA escolhido (Grau de Aprendizado - GA) quanto do impacto provável dos mesmos sobre o sucesso profissional que os alunos almejam (Grau de Importância - GI). 
Por fim, a efetividade da disciplina foi estimada em função dos atributos que tiveram, ao mesmo tempo, alto GA e GI.

Figura 1: Explicação esquemática da pesquisa.

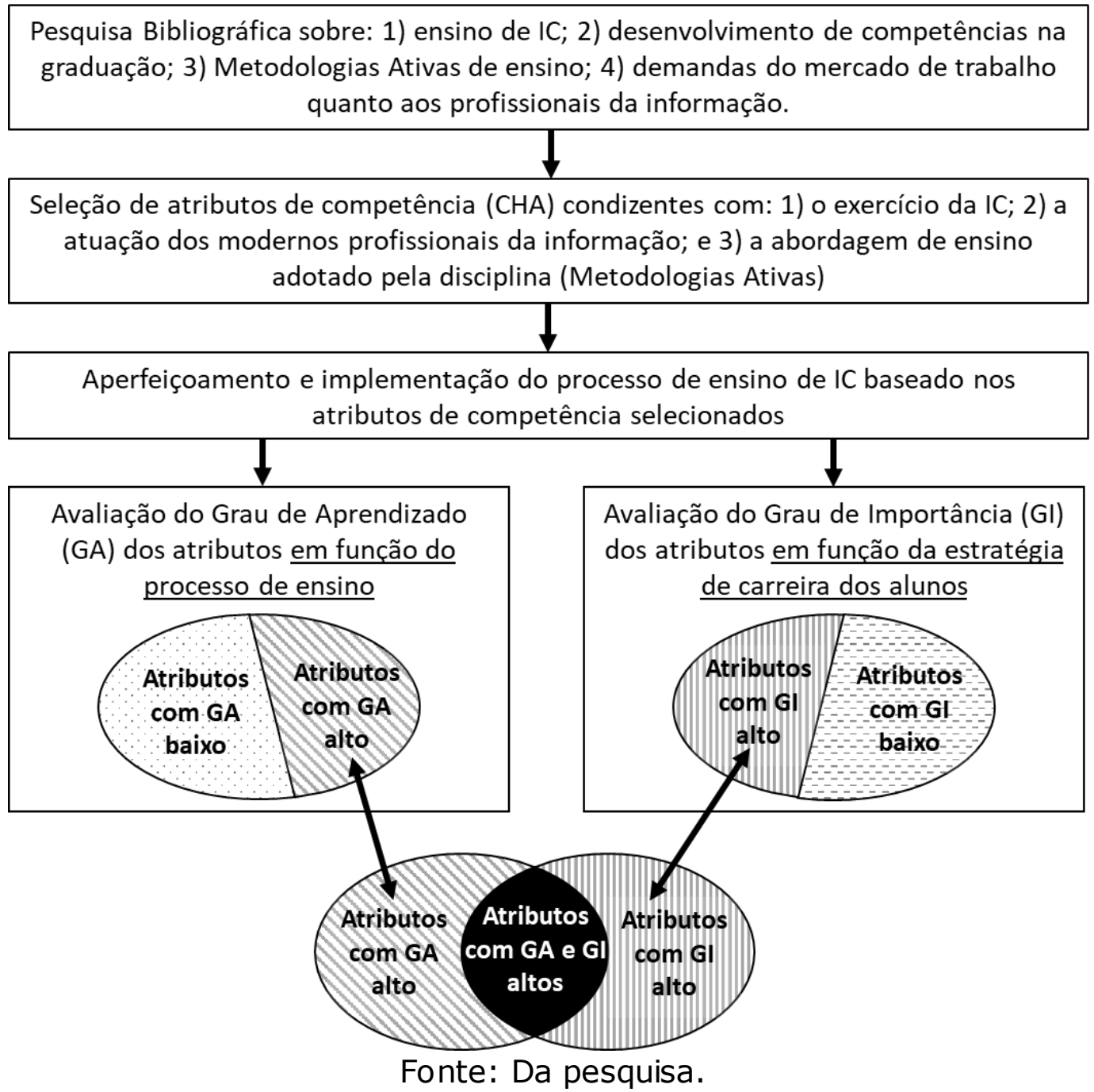

Dada a ausência de pesquisas que relacionem o ensino em IC na graduação ao aprendizado de atributos de competência relevantes ao sucesso profissional dos alunos, há muito desconhecimento em torno do objeto dessa pesquisa. Sendo assim, seu benefício central reside em lançar luz sobre essa problemática, permitindo uma melhor compreensão do fenômeno e o estabelecimento de hipóteses sobre as relações causais mais relevantes. Por essa razão, essa pesquisa foi classificada como exploratória:

Essas pesquisas têm como objetivo proporcionar maior familiaridade com o problema, com vistas a torná-lo mais explícito ou a construir hipóteses. Pode-se dizer que estas pesquisas têm como objetivo principal o aprimoramento de ideias ou a descoberta de intuições (GIL, 2007, p. 41). 
Além disso, considerando o objetivo traçado para o trabalho, sua realização exigiria o envolvimento tanto do docente-pesquisador quanto dos alunos-participantes. Dessa forma, decidiu-se pela adoção da Pesquisa-Ação como método, já que a mesma é voltada a trabalhos:

(...)com base empírica concebida e realizada em estreita associação com uma ação ou com a resolução de um problema coletivo e no qual os pesquisadores e os participantes representativos da situação ou problema estão envolvidos de modo cooperativo ou participativo (THIOLLENT, 2009, p. 16).

Organizada de acordo com a Pesquisa-Ação, o trabalho seguiu as etapas indicadas no Quadro 2, a seguir.

Quadro 2:Etapas da pesquisa-ação e sua forma específica de aplicação nesse trabalho.

\begin{tabular}{|c|l|}
\hline Etapas da Pesquisa & \multicolumn{1}{|c|}{ Atividadesda Pesquisa } \\
\hline Etapa Exploratória & $\begin{array}{l}\text { Para a delimitação do campo de investigação, realizou-se um levantamento } \\
\text { bibliográfico sobre o ensino de IC, as metodologias ativas,o desenvolvimento de } \\
\text { competências na graduação e a gestão de carreiras. Além disso, já na primeira } \\
\text { aula foi realizado um debate sobre a proposta da disciplina, de modo a } \\
\text { compatibilizar as expectativas do docente-pesquisador com as dos alunos- } \\
\text { participantes do processo de ensino. }\end{array}$ \\
\hline $\begin{array}{c}\text { Pormulação do } \\
\text { Problemae } \\
\text { do Trabalho }\end{array}$ & $\begin{array}{l}\text { Em paralelo à etapa exploratória,foi delimitado o objetivo da pesquisa, idêntico } \\
\text { ao expresso na introdução desse trabalho. A disciplina foi então adaptada e } \\
\text { implementada e seus resultados quanto ao CHA, avaliados ao final do semestre } \\
\text { pelos próprios alunos. As características principais desse processo de ensino } \\
\text { estão descritas na próxima seção. }\end{array}$ \\
\hline Seleção de Amostra & $\begin{array}{l}\text { Quanto à amostragem para a coleta de dados, essa foi desnecessária, uma vez } \\
\text { que todos os seis alunos matriculados na disciplina fizeram parte do estudo. }\end{array}$ \\
\hline Coleta de Dados & $\begin{array}{l}\text { O instrumento principal de coleta de dados foi um questionário, respondido } \\
\text { pelos alunos no final da disciplina. O questionário era composto por três } \\
\text { quadros, cada um relativo às listas do CHA (Conhecimento, Habilidade e } \\
\text { Atitude)adotados pela disciplina.Para cada atributo contido nos quadros, os } \\
\text { alunos tinham que indicar tanto o GA quanto o Gl. Cada uma das variáveis tinha } \\
\text { cinco níveis diferentes (vide seções 5.2 e 5.3). } \\
\text { Um segundo processo de coleta foi realizado por meio do acesso ao histórico de } \\
\text { mensagens de um grupo privado, criado no Facebook para a realização de } \\
\text { debates sobre o significado e os meios para se alcançar o sucesso profissional } \\
\text { almejado por cada aluno. }\end{array}$ \\
\hline Análise dos Dados & $\begin{array}{l}\text { Os dados dos questionários foram tabulados e analisados em cada um dos três } \\
\text { tipos de atributo, segundo cada um dos cinco níveis do GA e do Gl. Na }\end{array}$ \\
\hline
\end{tabular}




\begin{tabular}{|c|l|}
\hline & $\begin{array}{l}\text { sequência, os percentuais dos atributos foram calculados e seus significados, } \\
\text { discutidos nas seções5.2 e 5.3. } \\
\text { Quanto aos dados obtidos via Facebook, os mesmos analisados à luz da proposta } \\
\text { estruturada de debates denominada “Roteiro para o Sucesso" (vide seção 5.1). }\end{array}$ \\
\hline $\begin{array}{c}\text { Realização de } \\
\text { Seminários }\end{array}$ & $\begin{array}{l}\text { A fim de identificar oportunidades de melhoria para o processo de ensino, bem } \\
\text { como esclarecer dúvidas quanto ao significado das respostas dos alunos, foi } \\
\text { realizada na última aula da disciplina uma discussão com toda a turma sobre os } \\
\text { resultados do questionário e do grupo privado do Facebook. }\end{array}$ \\
\hline $\begin{array}{c}\text { Divulgação dos } \\
\text { Resultados }\end{array}$ & O presente trabalho tem justamente essafunção. \\
\hline
\end{tabular}

Fonte: Adaptado de Gil (2007).

\section{Resultados e discussão}

\subsection{Resultados da implementação do "Roteiro para o Sucesso"}

O principal bloco de debates do "roteiro para o sucesso" é o de autoconhecimento, o qual foi dividido em várias fases, correspondentes a cada semana de implementação do roteiro. Nafase inicial de debates,focada no autoconhecimento e sua relação com a vida profissional, os alunos discutiram a importância da conexãode cada um com asua visão de carreira. Essa discussão gerou boas oportunidades de descobertasobre o que o sucesso profissional realmente significa para cada um, independente das preferências familiares, da sociedade, etc.

Nessa fase, os alunos compartilharam com os colegas os insights que puderam extrair dos questionários indicados pelo professor como provocações para reflexão de cada um sobre suas características pessoais e a influência das mesmas sobre suas carreiras desejadas. Os questionários foram: 1) inventário de personalidade de David Keirsey; e 2) levantamento de indinações profissionais, de Edgar H. Schein. Um dos alunos postou o seguinte:

Meu primeiro teste não conseguiu ilustrar meus pontos fortes e fracos ou pontos teoricamente que "batem" com meu modus operandi, porém, alguns pontos me deixaram inquieto e reflexivo...

- Ser inquieto.

- Impulsivo para a execução de algumas ações.

- Grande habilidade com instrumentos de precisão.

Estes pontos me chamaram a atenção, me fazendo analisar estes pontos com situações do meu cotidiano ou atitudes que já executei... ilustrando de forma mais clara o teste, por mais que não concorde completamente com o teste ele me deu uma base maior 
para compreender o segundo e fazer link com este primeiro resultado.

Os três ciclos de debate que se seguiram foram dedicados à aplicação das ideias de Missão, Visão e Valores à realidade de cada um. Todos os alunos discutiram conceitos de Missão, Visão e Valores obtidos por eles na literatura. Na sequência, eles elaboraram seus próprios conceitos de Missão profissional, Visão Profissional e Valores profissionais, inspirados nos conceitos organizacionais mas direcionados ao contexto das carreiras individuais. Diante dos conceitos individuais, cada um apresentava suas opiniões e sugeria ajustes. Eis um exemplo de um dos conceitos formulados pelos próprios alunos:

Se missão é o sentido que nos move, a visão é a direção de onde queremos chegar profissionalmente. Ter uma direção é tão importante quanto ter um sentido.

O próximo ciclo de debates teve como foco o desejo genuíno de crescer e ser bem-sucedido profissionalmente, latente em cada um de nós mas que, às vezes, é desconhecido por nós mesmos. Ao discutir esse assunto com os colegas de turma, os alunos confrontaram certos tabus e falaram mais abertamente sobre como percebiam suas reais possibilidades de sucesso.

Ao mesmo tempo em que a origem e a relevância da real motivação para o sucesso profissional estavam sendo discutidas, foi requisitado aos alunos que resgatassem suas opiniões e insights dos debates anteriores e documentassem as respostas às perguntas 1 e 2 da sua estratégia de carreira (vide Quadro 1). Desse modo, a partir daquela semana a estratégia começou a ser definida (e redefinida, uma vez que as ideias de cada um a respeito do verdadeiro significado do sucesso profissional foram emergindo como num processo de descoberta, com idas e vindas ao longo de todo o percurso na disciplina).

O término dessa fase de autoconhecimento foi marcado pelo resgate das discussões anteriores e a definição das forças (pergunta 3do Quadro 1) e fraquezas (pergunta 4) mais confiáveis e relevantes frente às perguntas 1 e 2.Na sequência, o grupo debateu oportunidades e ameaças relevantes às suas estratégias profissionais, com destaque para a indicação de fontes e outros insights com o potencial de serem úteis aos colegas:

As principais fontes utilizadas para acrescentar em minhas ameaças e oportunidades foram minhas poucas, porém válidas experiências de trabalho com relatórios e feedbacks dados por supervisores e LinkedIn. E experiências pessoais também foram válidas para esta busca de ameaças e oportunidades. 
De posse das informações essenciais sobre si próprio e sobre o ambiente profissional no qualindicou interesse, cada aluno se dedicou à construção propriamente dita da sua estratégia profissional. Como dito a eles no início da disciplina, essa estratégia deveria representar o caminho que, na opinião de cada um, poderia levá-loa alcançar o sucesso profissional que almejada melhor forma possível.

Os debates durante a criação da estratégia giraram em torno das ideias sobre o que fazer a respeito das forças, fraquezas, ameaças e oportunidades observadas por cada um, bem como sobre a maneira de selecionar as ideias mais factíveis, as de maior impacto/alavancagem, e as mais capazes de gerar ou fortalecer em cada um suas competências distintivas:

quais são as principais ações a serem tomadas para que o seu Montando a minha estratégia de carreira percebi um detalhe interessante que acho muito válido de compartilhar com vocês: sejam simples... como essa parte da atividade é extremamente pessoal e particular de cada um de nós, cabe a cada um pensar, refletir e analisar com calma objetivo se realize. Para que isso seja possível, sejam simples, diretos, práticos e objetivos, agora é a hora de fazer! Conquistar! Realizar!

O último ciclo de debates permitiu a troca de percepções entre os alunos sobre o processo de construção da estratégia, seus percalços e sua relevância. Representa o espírito desses debates finais o seguinte depoimento de um dos alunos:

Ao longo de toda essa disciplina, realizando mudanças, melhorias e aperfeiçoamentos na estratégia cheguei a seguinte conclusão: É simplesmente impossível realizar esse exercício sem refletir dois aspectos essenciais da sua vida! Quem você verdadeiramente é e como a partir disso você irá alcançar aquilo que deseja profissionalmente.

A própria natureza do exercício nos convida a refletir constantemente sobre isso, pois semanalmente ou até mesmo diariamente realizamos mudanças na atividade baseado nas nossas mudanças de perspectivas, novas visões, novos objetivos e descrevemos, passamos para o papel todas as nossas projeções, todo esse planejamento.

Todas as perguntas necessárias para o preenchimento da atividade auxiliaram muito a compreender melhor o que quero, para onde ir. Muito legal!

Especificamente no que diz respeito ao funcionamento do grupo fechado da disciplina no Facebook, o mesmo operou por 16 semanas. Nesse período, o professor-pesquisador realizou 88 postagens, enquanto 
os seis alunos matriculados na disciplina postaram 258 vezes (o que corresponde a mais que 16 postagens por semana). Além disso, houve 497 curtidas em comentários (pouco mais que 31 por semana) e 24 links ou documentos compartilhados entre os participantes do grupo $(1,5$ por semana).

O fechamento das atividades concernentes ao sucesso profissional dos alunos ocorreu na última aula, com a entrega de suas estratégias profissionais e a apresentação das mesmas à turma no estilo Pecha Kucha. Os resultados em sala de aula foram excelentes, corroborando assim os depoimentos dados no Facebook sobre o quanto as discussões sobre carreira foram relevantes para eles.

O sucesso dessas atividades também contribuiu para a qualificação da avaliação do GI, uma vez que o maior discernimento sobre seus próprios ideais de carreira habilitava cada aluno a determinar com maior segurança quais atributos de competência teriam o maior GI.

\subsection{Avaliação do Grau de Aprendizado (GA)dos atributos}

O Quadro 3 exibe os doze atributosdeconhecimento que compõem o CHA da disciplina, bem como a avaliação, feita pelos próprios alunos, do aprendizado em cada atributo. Na explicação do questionário de avaliação, foi esclarecido que o objetivo era descobrir o quanto cada aluno acreditava ter aprendido/se desenvolvido em cada atributo em função da disciplina.

As colunas "Grau de Aprendizado em função da disciplina (\%)", numeradas de 1 a 5 , representam os percentuais correspondentes ao número de alunos que indicaram cada um dos cinco GAs estabelecidos pela pesquisa:1 - Nenhum aprendizado ou aprendizado muito pequeno; 2 - Aprendizado baixo/insuficiente; 3 - Aprendizado bom/adequado; 4 Aprendizado muito bom; e 5 - Aprendizado excelente, além das expectativas.

Após a tabulação e cálculo dos percentuais para cada GA, foram introduzidas duas novas colunas à direita do quadro. A primeira, com o rótulo " $(1+2)$ ", representa a soma dos percentuais mais baixos de aprendizado (i.e., os graus 1 e 2). Já a segunda - rótulo "(4+5)" consiste na soma dos percentuais mais altos (graus 4 e 5). Desse modo, essas duas colunas indicam os sucessos e as falhas mais expressivos da disciplina, no que diz respeito ao aprendizado dos atributos:

-Atributos com percentual considerável na coluna " $(1+2)$ " indicam que boa parte da turma aprendeu nada ou muito pouco sobre eles, configurando assim forte indício de falha; 
- Já os atributos com percentual considerável na coluna " $(4+5)$ " indicam que boa parte da turma aprendeu muito sobre eles, constituindo um indício de sucesso.

Quadro 3: Conhecimentos avaliados em função do grau de aprendizado dos alunos.

Cód.

\section{Conhecimentos Avaliados}

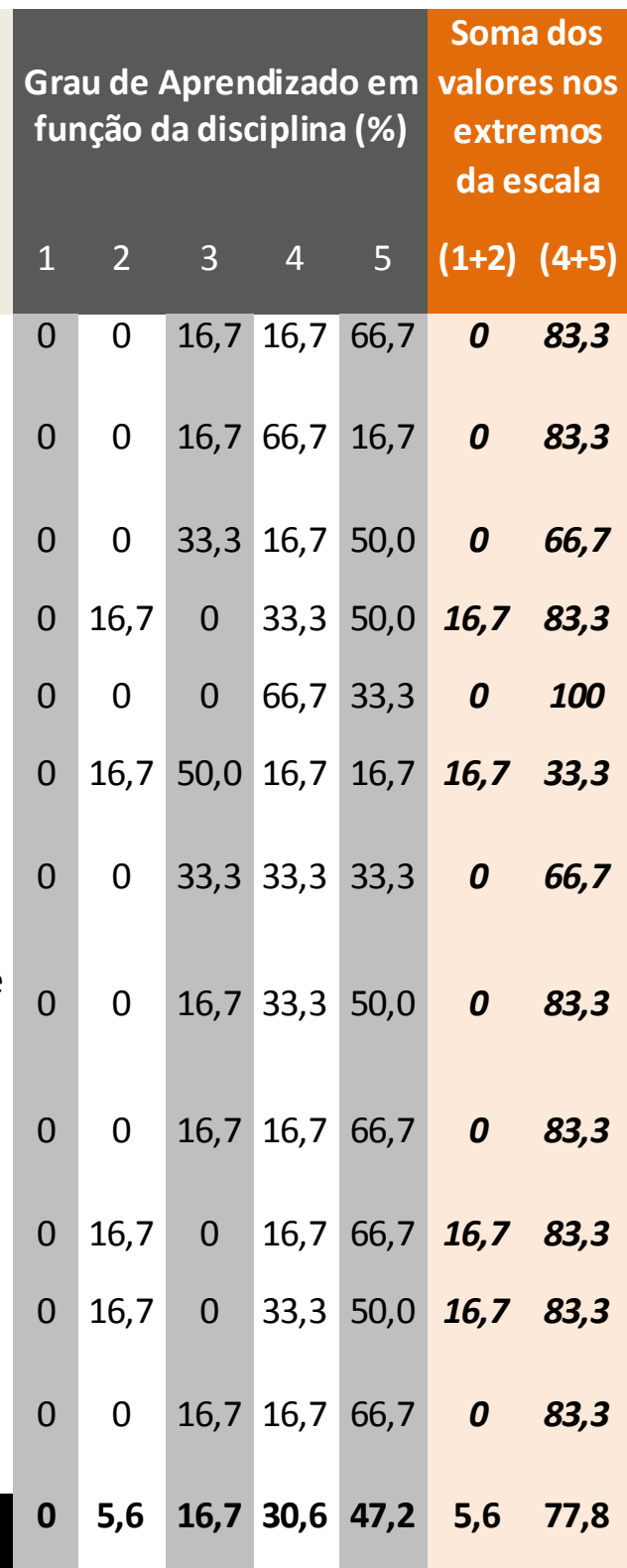

\section{MÉDIA DOS PERCENTUAIS (\%)}

Fonte: Da pesquisa.

Os primeiros sete atributos dizem respeito ao ciclo de IC. Uma vez que 0 ciclo representa as fases do processo de realização da Inteligência(OLIVEIRA;LACERDA,2007), o GA dos alunos nesses atributos indica o quanto eles compreenderam a realização do processo de IC. Com base nesse suporte teórico é que os projetos-piloto foram realizados. Portanto, quão melhores forem os resultados da aprendizagem nesses 
atributos, maiores as chances da prática ser construtiva e bem-sucedida (e vice-versa).

Pela observação da coluna "(4+5)" do Quadro 3, nota-se que, a não ser pelo atributo "C6" (Disseminação de IC: o que é e como realizar na prática), o GA dos alunos quanto ao ciclo de IC foi majoritariamente muito bom ou excelente. A utilização da metodologia ativa orientando a realização de projetos-piloto numa organização real foi provavelmente decisiva para esse resultado. Por outro lado, o resultado em "C6" indica a necessidade de revisão da abordagem adotada para o ensino e a realização prática da disseminação dos resultados produzidos pelos alunos.

Os atributos "C8" (O ambiente interno da organização analisada: o que é e seus aspectos principais) e "C9" (O ambiente externo da organização analisada: o que é e seus aspectos principais) dizem respeito ao conhecimento alcançado pelos alunos sobre o ambiente interno e externo da organização estudada.Como esses não são conteúdos ministrados nas aulas, esses atributos de conhecimento são fruto da própria investigação dos alunos em suas atividades diagnósticas e de IC. É por esse motivo que o GA nesses atributos expressa o sucesso (ou fracasso) da utilização da metodologia ativa pelos alunos: quão maior o GA autônomo dos estudantes, mais efetiva terá sido a utilização da metodologia ativa (e vice-versa). Sendo assim, os resultados são muito satisfatórios, uma vez que o GA dos alunos nesses atributos ficou compreendido quase exclusivamente entre o muito bom e o excelente.

Em função do uso da técnica de contraposição das estratégias formal e informal da organização estudada, os atributos "C10" (Estratégia formal/oficial da organização analisada) e "C11" (Estratégia informal/real da organização analisada) foram acrescidos à pesquisa. Assim como em "C8" e "C9", o conhecimento dos alunos sobre esses atributos resultou única e exclusivamente de suas próprias investigações. E, assim como nos atributos anteriores, aqui o GA dos alunos foi quase exclusivamente muito bom ou excelente.

Esse grande aprendizado nos últimos quatro atributos não indica apenas o sucesso da busca dos alunos pela construção do seu próprio conhecimento. Ele também indica a ampliação do conhecimento sobre a organização estudada e seu contexto estratégico. Não fosse pela disciplina, eles só alcançariam tal compreensão se ocupassem cargos elevados na hierarquia da organização (o que normalmente não acontece com os nossos alunos durante sua graduação). Desse modo, é possível supor que a experiência da disciplina aproxima nossos futuros egressos do exercício de funções estratégicas nas organizações, uma vez que concede a eles a oportunidade de acumular conhecimentos típicos (e necessários) ao desempenho das mesmas. 
O último atributo (C12 - Estratégia profissional: o que é e como construir a sua própria) expressa o aprendizado acumulado pelos alunos quanto ao seu próprio sucesso profissional, desde o seu significado até o caminho para atingi-lo. O alto GA em torno desse atributo (83,3\% da soma entre muito bom e excelente) indica o grande aprendizado dos alunos em torno da ideia de sucesso profissional (vide seção 5.1) foram bem-sucedidas.

Vale destacar que a maioria desses atributos tiveram ao menos uma resposta associada ao grau 3 (aprendizado bom/adequado), apesar desse grau não ter gozado do mesmo nível de incidência observada para os graus 4 e, principalmente, 5. Destaca-se, no entanto, o atributo "C6", posicionado por metade dos alunos como grau 3.

Por fim, nenhum dos atributos de conhecimento teve resultado na coluna " $(1+2)$ " superior a $16,7 \%$, corroborando assim as análises prévias que apontam um excelente grau médio de aprendizado dos conhecimentos avaliados na pesquisa.

O Quadro 4 apresenta a avaliação do GAdas habilidades do CHA da disciplina. Diferente do observado para os conhecimentos, no caso das habilidades encontramos três atributos cuja soma dos graus de aprendizado mais altos é de apenas 33,3\%. São eles: "H5" (Construir implicações após compreender o contexto por meio da análise de IC), "H9" (Discernir os verdadeiros objetivos estratégicos e a verdadeira estratégia da organização analisada) e "H10" (Descobrir consonâncias e dissonâncias entre as estratégias oficial e real da organização analisada).

Além disso, "H5" e "H10" também possuem uma soma alta dos graus de aprendizado mais baixos $(33,3 \%)$, o que faz desses os atributos de habilidade mais carentes de ajustes no âmbito da disciplina. Outros quatro atributos $(\mathrm{H} 1, \mathrm{H} 2, \mathrm{H} 6 \mathrm{e} \mathrm{H} 13)$ possuem a soma dos graus de aprendizado mais altos igual a $50 \%$, um valor positivo porém passível de ampliação, o que indica haver a necessidade de melhoria das ações de ensino vinculadas a eles.

Quadro 4: Habilidades avaliadas em função do grau de aprendizado dos alunos.

\begin{tabular}{|c|c|c|c|c|c|c|}
\hline \multirow[t]{2}{*}{ Cód. } & \multirow[t]{2}{*}{ Habilidades Avaliadas } & \multicolumn{4}{|c|}{$\begin{array}{l}\text { Grau de Aprendizado em } \\
\text { função da disciplina (\%) }\end{array}$} & \multirow{2}{*}{$\begin{array}{l}\text { Soma dos } \\
\text { valores nos } \\
\text { extremos } \\
\text { da escala } \\
(1+2)(4+5)\end{array}$} \\
\hline & & 12 & 3 & 4 & 5 & \\
\hline $\mathrm{H} 1$ & Coletar informações de fontes humanas e documentais & $0 \quad 16,7$ & 33,3 & 16,7 & 33,3 & $16,7 \quad 50,0$ \\
\hline $\mathrm{H} 2$ & $\begin{array}{l}\text { Avaliar o grau de confiabilidade de dados e } \\
\text { informações }\end{array}$ & 016,7 & 33,3 & 16,7 & 33,3 & $16,7 \quad 50,0$ \\
\hline
\end{tabular}


H3

de IC

$\mathrm{H} 4$

Construir conclusões e argumentos com lógica e rastreabilidade

Construir implicações após compreender o contexto por meio da análise de IC

H6

Construir recomendações baseadas em implicações extraídas da análise de IC

$\mathrm{H} 7$

Descrever, em linhas gerais, o ambiente interno da organização analisada

$\mathrm{H} 8$

Descrever, em linhas gerais, o ambiente externo da organização analisada

H9

Discemir os verdadeiros objetivos estratégicos e a verdadeira estratégia da organização analisada

Extrair, dos resultados da IC, ideias e oportunidades para alavancar o sucesso da organização analisada

H12 Criar sua própria estratégia profissional

Extrair, dos resultados da IC, ideias e oportunidades para alavancar o seu próprio sucesso

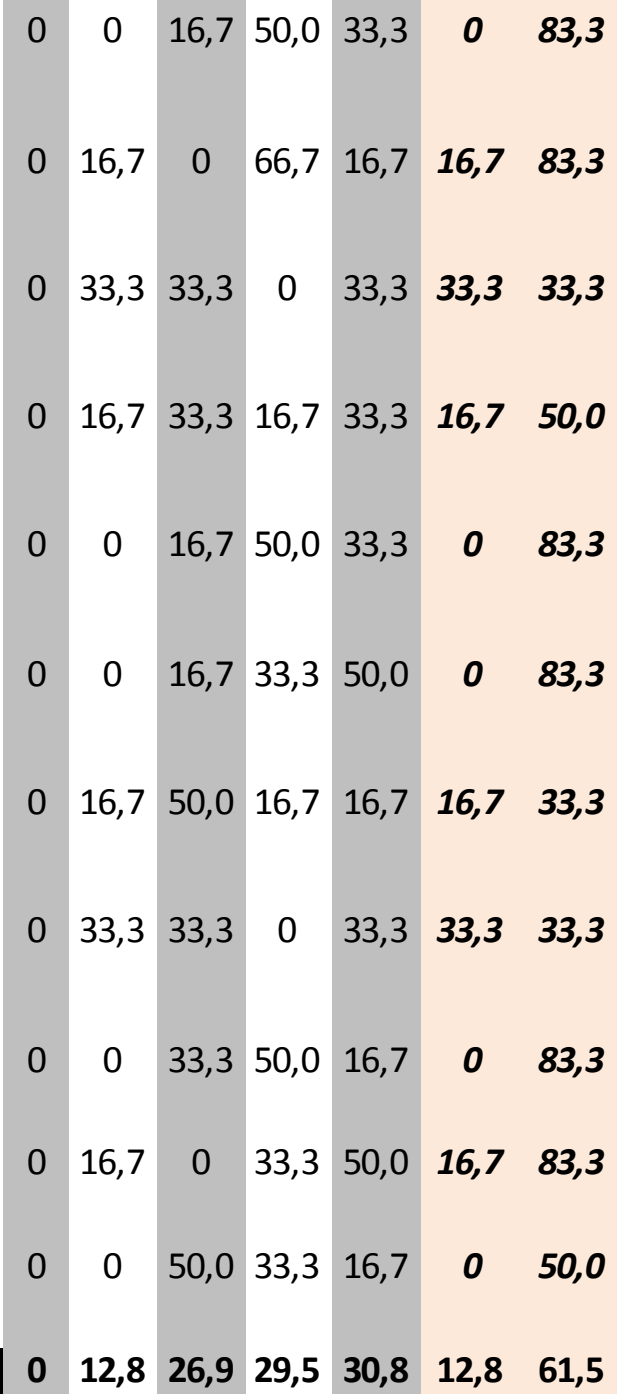

Fonte: Da pesquisa.

\section{MÉDIA DOS PERCENTUAIS (\%)}

A análise do quadro mostra ainda uma ampliação do percentual do grau 3: enquanto a média para esse grau frente aos atributos de conhecimento (vide última linha do Quadro 3) ficou em 16,7\%, para as habilidades essa média quase dobrou, saltando para 26,9\%. Além disso, esse aumento veio às custas da redução do percentual do grau 5 (já que essa foi a única categoria com redução, passando de $47,2 \%$ para $30,8 \%$ ), o que indica uma diminuição sistemática do aprendizado em comparação aos atributos de conhecimento. Destacam-se nesse contexto os atributos "H9" e "H13" (Extrair, dos resultados da IC, ideias e oportunidades para alavancar o seu próprio sucesso), ambos com avaliação no grau 3 igual a $50 \%$.

Em suma, o Quadro 4 revela uma maior dificuldade da disciplina em apoiar o desenvolvimento de habilidades em comparação com os conhecimentos. Apesar do uso da metodologia ativa e das diferentes práticas de integração entre teoria e prática, não seria de se espantar que 
o tempo para a assimilação de habilidades tão sofisticadas como as aqui estudadas fosse superior àquele necessário para a apreensão de conhecimentos. Em todo caso, há que se revisar o modo com que as habilidades são trabalhadas no âmbito da disciplina, de modo a promover uma melhoria desses resultados.

A seguir são tecidos comentários sobre alguns atributos específicos. Os atributos "H1" (Coletar informações de fontes humanas e documentais) e "H2" (Avaliar o grau de confiabilidade de dados e informações) estão relacionados tanto à coleta em si quanto à avaliação da confiabilidade das informações obtidas. Como os resultados apontam para a necessidade de melhoria, a introdução de novos exemplos de coleta em diversas fontes, bem como da avaliação da confiabilidade das mesmas, poderá criar um impacto positivo sobre a efetividade da disciplina nesses quesitos e até impulsionar uma das competências mais demandadas na atualidade: a capacidade de lidar criticamente com as "Fake News".

Os atributos "H5" e "H6" (Construir recomendações baseadas em implicações extraídas da análise de IC) dizem respeito à análise de informações, considerada a fase mais complexa do processo de IC e, portanto, de difícil aprendizado por iniciantes. Uma solução para potencializara compreensão é intensificar o uso dos próprios projetospiloto dos alunos como ferramenta de consolidação dessas habilidades. Essa prática já é realizada, mas há espaço para aperfeiçoamentos e aumento da sua importância no cômputo do processo de ensino.

Por fim, o atributo "H13" (Extrair, dos resultados da IC, ideias e oportunidades para alavancar o seu próprio sucesso) recebeu uma avaliação que poderia ter sido melhor. Considerando que vários alunos não atuarão profissionalmente após a graduação nas organizações que analisaram na disciplina, seria de se esperar que os resultados obtidos especificamente para essas organizações não fossem em grande parte úteis para o sucesso profissional dos mesmos. Por outro lado, a oportunidade de realização dos estudos e o aprendizado consequente podem abrir oportunidades futuras interessantes. Como a avaliação desse atributo não foi propriamente ruim mas apenas limitada, pode ser que a mesma seja um reflexo do equilíbrio entre as duas causas supracitadas.

O Quadro 5 trata da terceira dimensão do CHA: as atitudes. Determinantes para os comportamentos e conhecidas por serem de difícil alteração, as atitudes são indispensáveis à prática de IC e também à obtenção do sucesso profissional. Cada vez mais as atitudes são consideradas na concessão de aumentos salariais, promoções e outras oportunidades de crescimento profissional (DUTRA, 2019), de modo que esse aspecto do CHA é de extrema importância. 
Quadro 5: Atitudes avaliadas em função do grau de aprendizado dos alunos.

Cód.

Atitudes Avaliadas

Grau de Aprendizado
em função da disciplina
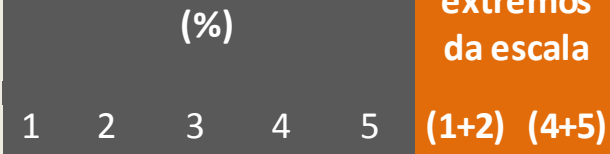

A1

Motivação/Ímpeto de compreender o ambiente intemo da organização analisada

A2 Motivação/Ímpeto de compreender o ambiente externo da organização analisada

A3

Pensamento analítico quanto aos assuntos da organização analisada

A4

Olhar estratégico sobre os assuntos-chave da organização analisada

A5

Senso crítico frente às decisões e/ou ações estratégicas da organização anal isada

A6

Discemimento para discutir assuntos estratégicos para a organização

A7

Confiança para participar de decisões e/ou ações

estratégicas para a organização

A8

Confiança e discernimento para contribuir com o sucesso da organização analisada

Consciência dos seus próprios desejos e sonhos profissionais

A10

Determinação para lutar pelo seu próprio sucesso profissional

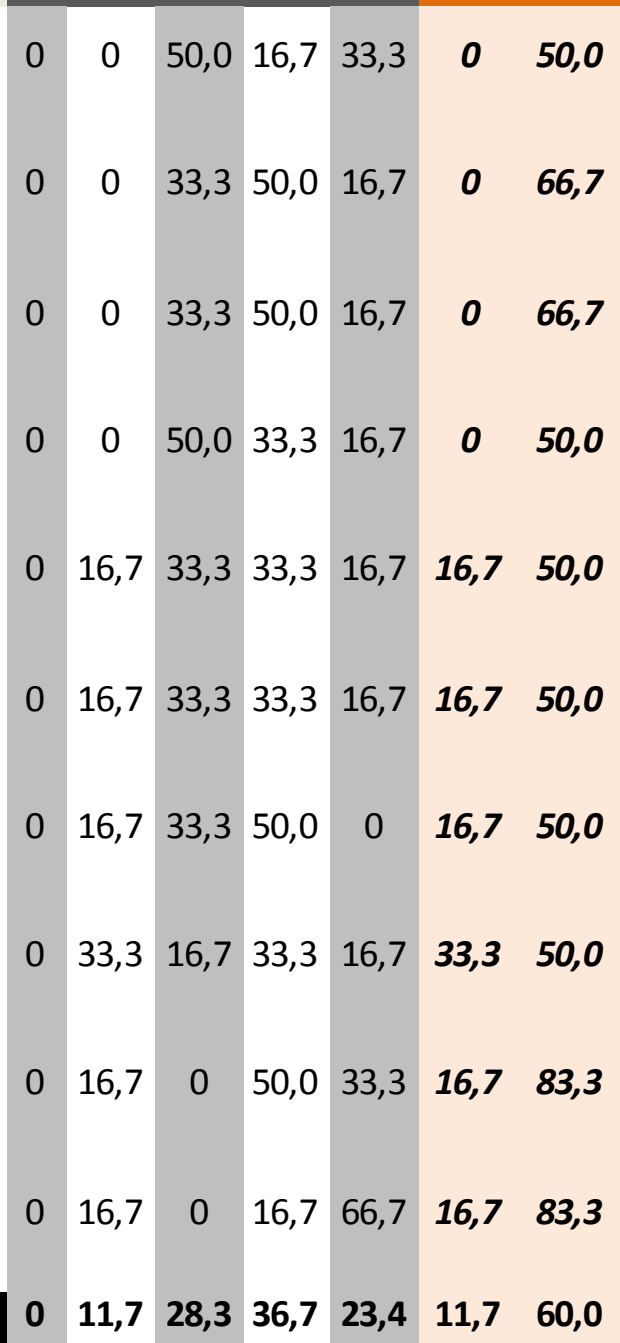

Fonte: Da pesquisa.

50,0

66,7

50,0
Soma dos

valores nos

extremos

da escala

$(1+2)(4+5)$

MÉDIA DOS PERCENTUAIS (\%)

O Quadro5 revela uma situação semelhante ao que se viu na avaliação do GA das habilidades: no geral o resultado foi bom, mas inferior ao observado para os conhecimentos. Em comparação, nota-se nas atitudes um pequeno aumento do percentual do grau 2 e um aumento do grau 3 em função da diminuição do grau 5. Mesmo frente às habilidades, o aprendizado das atitudes foi ligeiramente inferior: há um aumento do percentual do grau 4 decorrente de uma diminuição do grau 5. Em suma, dos três tipos de atributo, as atitudes são as que obtiveram menor GA no geral. 
A hipótese aqui é a mesma indicada para explicar o desempenho das habilidades: os resultados não tão expressivos devem-se a uma combinação entre a dificuldade inerente em impactar as atitudes dos indivíduos e as limitações da própria disciplina. Seu enfrentamento demanda melhorias na disciplina visando ao aperfeiçoamento da sua capacidade formativa no que tange aos comportamentos.

É interessante notar que os melhores resultados em termos do aprendizado das atitudes dizem respeito justamente aos atributos relacionados à busca do sucesso profissional: "A9" (Consciência dos seus próprios desejos e sonhos profissionais) e "A10" (Determinação para lutar pelo seu próprio sucesso profissional). Isso reforça a percepção da efetividade das atividades da estratégia profissional (Quadro 1) e do "Roteiro para o Sucesso" (Quadro 3).

\subsection{Avaliação do Grau de Importância (GI) dos atributos}

Como dito na metodologia, a análise do GI é relevante porque se considerarmos que cada aluno tem um ideal de carreira e de sucesso profissional, a eles não bastaria apenas alcançar altos graus de aprendizado: o ideal seria que tal aprendizado enfocasse atributos considerados por eles mesmos como importantes para o seu sucesso profissional.

Para a presente pesquisa, os graus de importância foram os seguintes:1 - Nenhuma importância (ou importância muito pequena); 2 Baixa importância; 3 - Boa importância; 4 - Muito importante; e 5Essencial/Indispensável (é um Fator Crítico de Sucesso para o seu sucesso profissional).

Essa análise se inicia com o Quadro 6, que indica o GI avaliado pelos alunos para cada um dos atributos de conhecimento. Assim como nos quadros da seção anterior, aqui também foram inseridas duas colunas à direita com o intuito de totalizar os percentuais dos graus de importância 1 e 2 - "(1+2)" - e dos graus 4 e 5 - "(4+5)". Desse modo, revela-se imediatamente os atributos de conhecimento avaliados como desimportantes pela maioria da turma (i.e., atributos com alto percentual na coluna " $(1+2) "$ ), bem como aqueles considerados relevantes (com alto percentual na coluna " $(4+5) "$ ").

Quadro 6: Conhecimentos avaliados em função do seu grau de importância para os alunos.

Cód.

Grau de Importância para o Sucesso Profissional do Aluno (\%)
Soma dos valores nos extremos da escala

$\begin{array}{lllllll}1 & 2 & 3 & 4 & 5 & (1+2) & (4+5)\end{array}$ 

C1 O que é Inteligência Competitiva (IC)

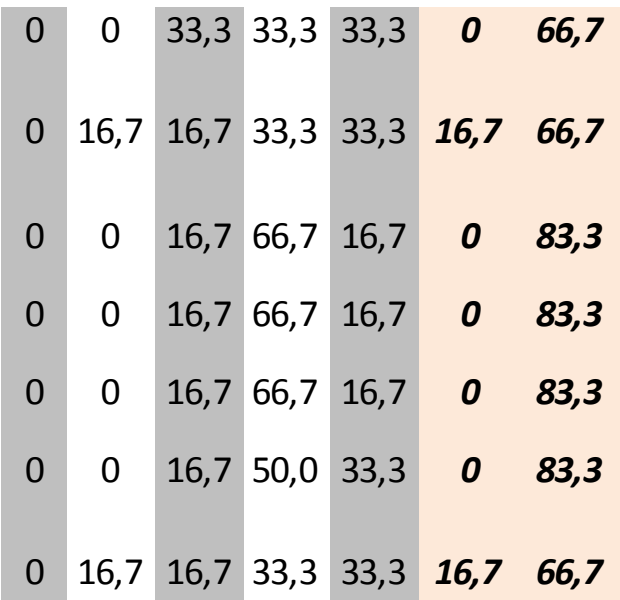
C8
Levantamento das Necessidades de IC: o que é e como realizar na prática
C3 Planejamento de IC: o que é e como realizar na prática
C4 Coleta de IC: o que é e como realizar na prática
C5 Análise de IC: o que é e como realizar na prática
C6 Disseminação de IC: o que é e como realizar na prática
C7 Avaliação do processo de IC: o que é e como realizar na prática
O ambiente interno da sua organização: o que é e seus aspectos principais
O ambiente externo da sua organização: o que é e seus aspectos principais
C10 Estratégia formal/oficial da sua organização
C11 Estratégia informal/real da sua organização
Estratégia profissional: o que é e como construir a sua própria
MÉDIA DOS PERCENTUAIS (\%)

Fonte: Da pesquisa.

Nota-se, pela última coluna do Quadro 6, que a soma dos graus de importância mais altos é dominante: dentre os 12 atributos, o pior avaliado em termos de importância (o atributo "C11" - Estratégia informal/real da sua organização) foi considerado muito importante ou essencial para o sucesso por metade dos alunos (e outros 33,3\% o consideraram com boa importância), o que não é ruim. Essa avaliação por parte dos alunos mostra que, independente das especificidades dos seus ideais de sucesso profissional, o conhecimento sobre como realizar a IC, como compreender melhor sua organização e seu contexto, e mesmo o autoconhecimento sobre suas próprias expectativas profissionais são considerados pela maioria como muito importantes para o alcance do sucesso profissional.

No que diz respeito à soma dos graus de importância na ponta inferior da escala, a quase totalidade dos atributos não ultrapassa o baixo percentual de $16,7 \%$. No entanto, justamente o atributo relacionado à análise da estratégia organizacional formal ("C10") teve uma concentração relevante de avaliações ruins. Como dito anteriormente, "C10" e "C11" correspondem à mesma técnica. Portanto, a combinação 
dos resultados de ambos indica a necessidade de revisão dessa abordagem no âmbito da disciplina.

Quanto ao GI das habilidades avaliadas (Quadro 7), os alunos julgaram-nas muito relevantes: a não ser por "H13", todos atributos expressaram baixa soma dos graus inferiores combinada a altas somas dos graus superiores (o grau 3 ocorreu para todos os atributos, mas excetuando os três últimos, o percentual foi baixo - apenas 16,7\%). Em outras palavras, na opinião da maioria dos alunos as habilidades de coletar e analisar informações sobre o ambiente interno e externo às organizações, bem como a de traçar sua própria estratégia profissional são muito relevantes para o seu próprio sucesso. Especificamente sobre "H13", o seu GI pode ter parecido menor para os alunos justamente pelo mesmo motivo que limitou o seu GA: o fato de vários deles não vislumbrarem uma atuação futura nas organizações que analisaram. Essa é uma questão em aberto, que carece de investigação complementar.

Quadro 7: Habilidades avaliadas em função do seu grau de importância para os alunos.

Cód.

Habilidades Avaliadas

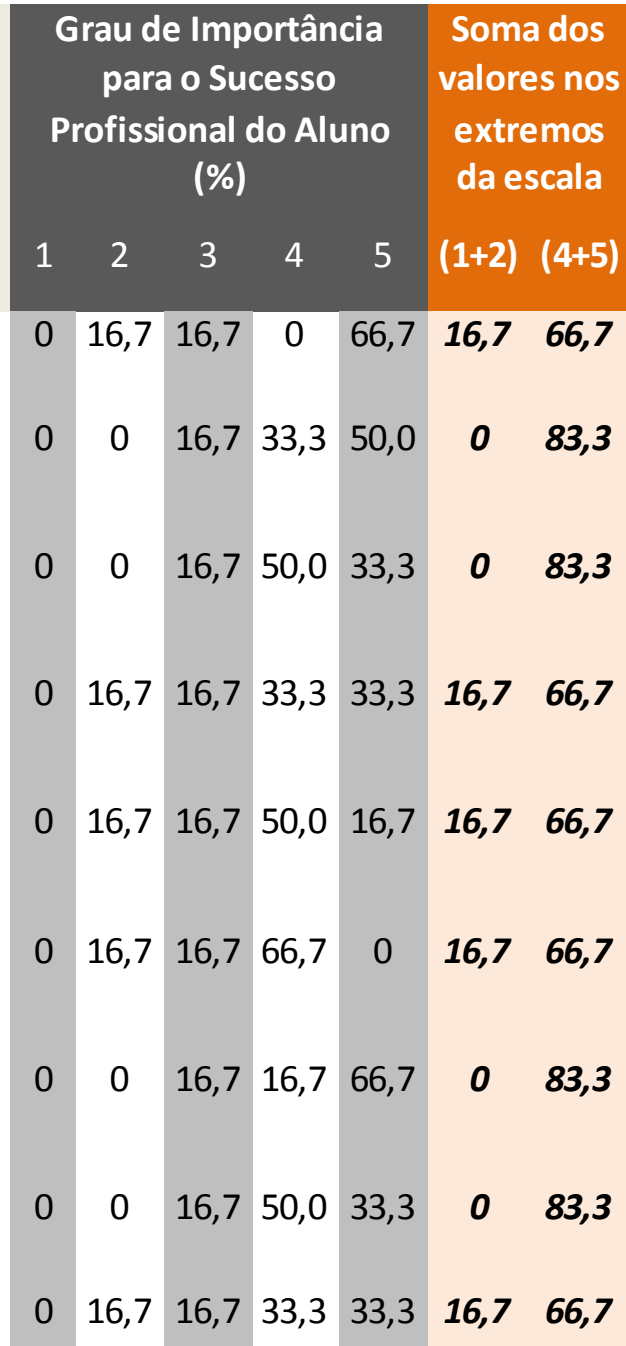

H9 Discemir os verdadeiros objetivos estratégicos e a Avaliar o grau de confiabilidade de dados e informações

Classificar e tratar informações coletadas para a análise de IC

H4 Construir conclusões e argumentos com lógica e rastreabilidade

Construir implicações após compreender o contexto por meio da análise de IC

Construir recomendações baseadas em implicações extraídas da análise de IC

Descrever, em linhas gerais, o ambiente interno da sua organização

Descrever, em linhas gerais, o ambiente externo da sua organização

$\begin{array}{llllll}16,7 & 16,7 & 33,3 & 33,3 & \mathbf{1 6 , 7} & \mathbf{6 6 , 7}\end{array}$ 
verdadeira estratégia da sua organização

H10 Descobrir consonâncias e dissonâncias entre as estratégias oficial e real da sua organização

Extrair, dos resultados da IC, ideias e oportunidades para alavancar o sucesso da sua organização

H12 Criar sua própria estratégia profissional

Extrair, dos resultados da IC, ideias e oportunidades

para alavancar o seu próprio sucesso

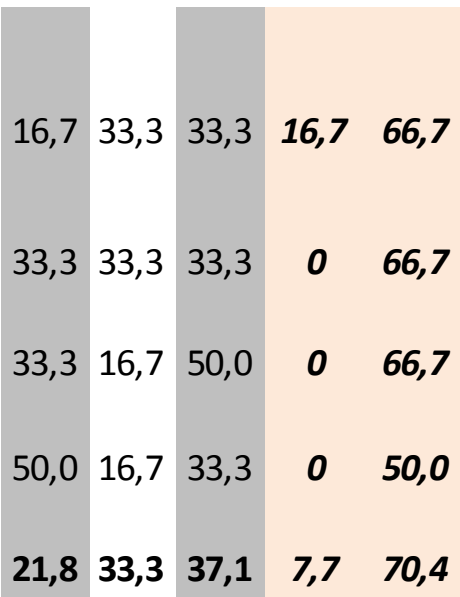

Fonte: Da pesquisa.

O Quadro 8 mostra o GI atribuído pelos estudantes às atitudes avaliadas. Apesar do aparente conflito em "A1" (Motivação/Ímpeto de compreender o ambiente interno da sua organização), para o qual um terço dos alunos atribuiu os dois graus de importância mais baixos e os outros dois terços, os dois graus mais altos, os demais atributos tiveram forte incidência dos graus de importância mais altos. Isso indica a compreensão, por parte dos alunos, da importância das atitudes para o sucesso profissional.

Sobre "A1", é possível que a polarização se deva ao fato de vários dos alunos não conectarem sua carreira à organização analisada. Não havendo tal conexão, a motivação para compreender o ambiente interno poderia ser menor para alguns. No entanto, se for esse o caso, o fato da maioria ter avaliado bem esse atributo indica que alguns alunos podem ter percebido que as mesmas técnicas aplicadas na disciplina poderiam ser replicadas futuramente, criando assim uma motivação não em função do conhecimento sobre a organização em si, mas pela construção da capacidade de obter esse conhecimento no futuro, quando estiverem atuando onde vislumbram um futuro promissor.

Em todo caso, é importante frisar a necessidade do aprimoramento da abordagem para a formação das atitudes, uma vez que foi nessa dimensão do CHA que ocorreu a maior discrepância entre o GI (em média, muito alto) e o GA (em média, o mais baixo dentre as três dimensões). 0 aperfeiçoamento das práticas já utilizadas para esse fim, bem como a reflexão sobre a inserção de práticas novas, deverão ser realizados antes do próximo ciclo de ensino da disciplina.

Quadro 8: Atitudes avaliadas em função do seu grau de importância para os alunos.

Cód.

Atitudes Avaliadas

Grau de Importância para o

Soma dos

Sucesso Profissional do

valores nos 


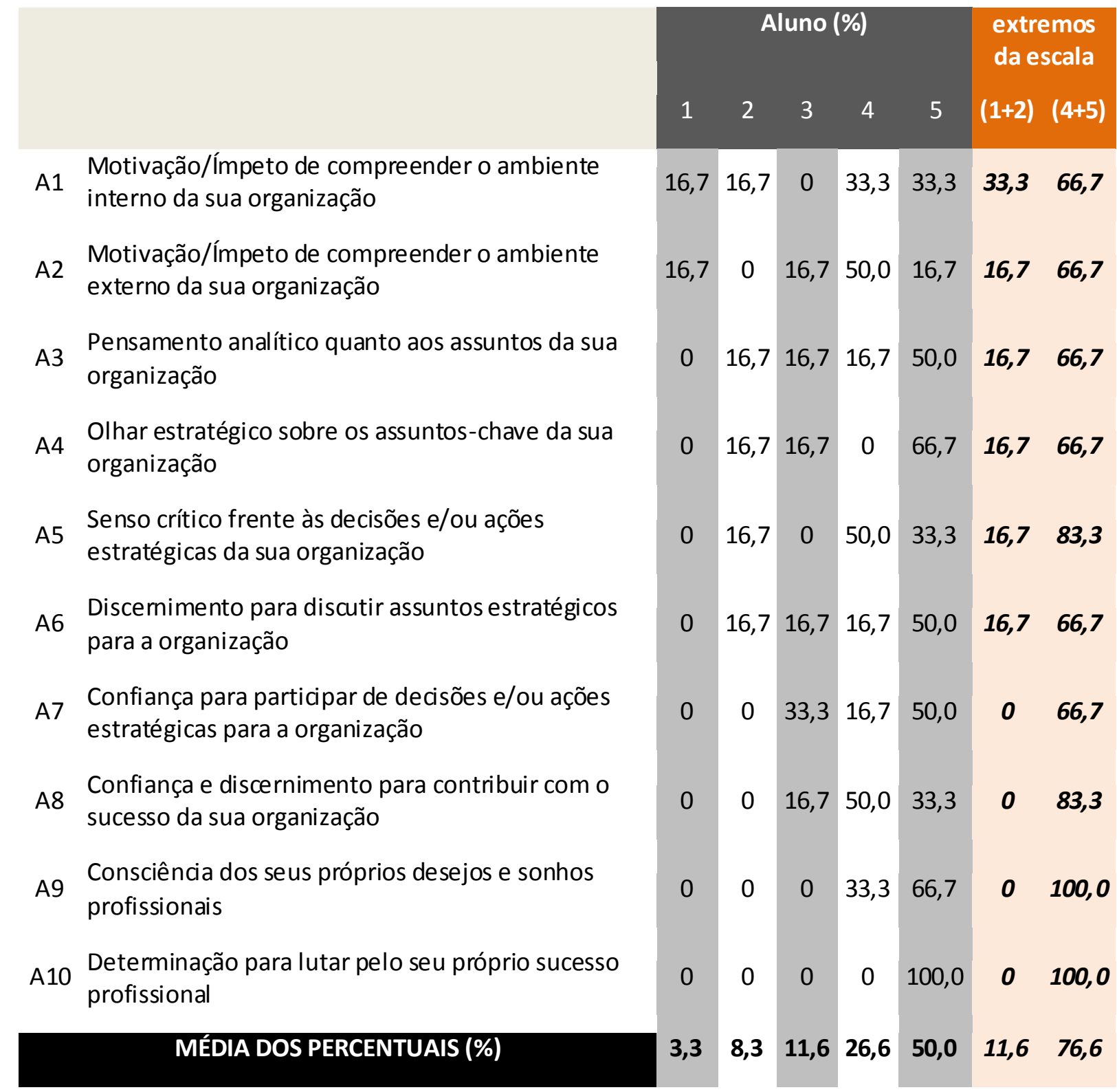

Fonte: Da pesquisa.

\subsection{Analisando GA e GI conjuntamente}

Após as análises do GA e GI separadamente, procedeu-se à sua análise conjunta. A Figura 2 mostra um gráfico de dispersão $X Y$ formado pelos atributos de conhecimento do $\mathrm{CHA}$ avaliado pelos alunos. Cada atributo teve suas médias ponderadas de GA e GI calculadas e, posteriormente, convertidas num ponto do gráfico, com GA como abscissa (ou coordenada horizontal) e GI como a ordenada (ou coordenada vertical).

Figura 2: Cruzamento entre os graus de aprendizado e de importância para os Conhecimentos. 


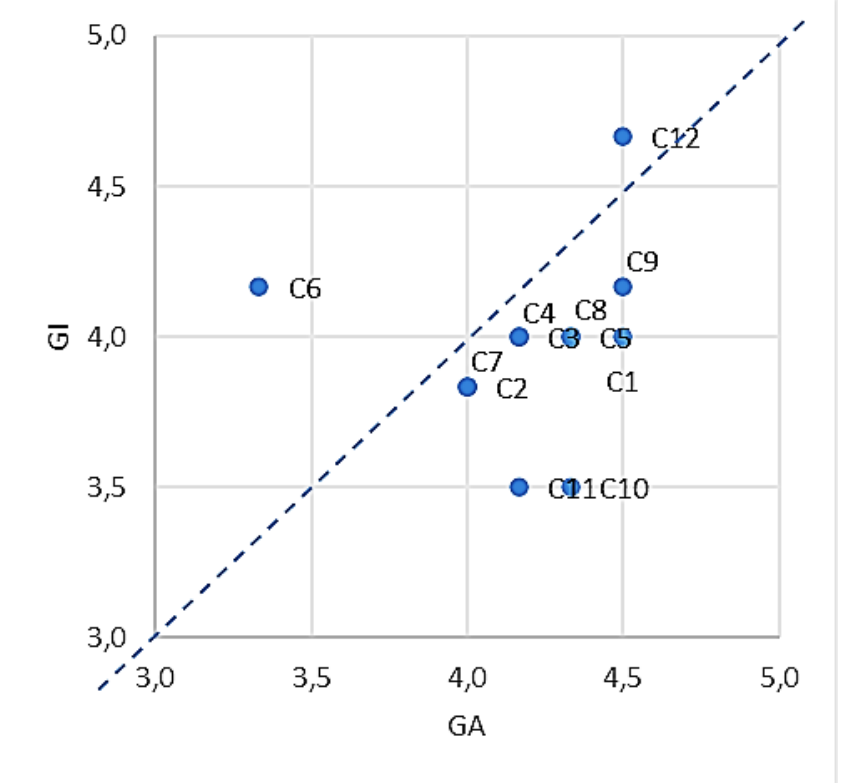

Fonte: Da pesquisa.

A figura mostra que a maioria dos GAs estão concentrados entre os valores 4,0 e 4,5 (com média de 4,2), e a maioria dos GIs concentram-se entre 3,5 e 4,2 (média de 4,0). Considerando que o GA igual a 4 significa "Aprendizado muito bom", e que GI igual a 4 indica que o atributo é muito importante para o sucesso profissional almejado, esse padrão de dispersão revela que os alunos acreditam que tiveram um aprendizado muito bom em torno de atributos de conhecimento muito importantes para o seu sucesso profissional.

Apesar do desempenho da disciplina ter sido positivo tanto para o GA quanto para o GI, os resultados de ambos não foram idênticos, como já vimos nas discussões dos Quadros 3 e 6. Com o auxílio da linha pontilhada (acrescentada à figura apenas para facilitar a análise), percebe-se que a maioria dos atributos de conhecimento possuem GA superior ao GI (em termos visuais, isso corresponde à presença maior de pontos no gráfico à direita da linha pontilhada).

Além disso,a análise de regressão linear simples gerou um coeficiente de determinação $\left(R^{2}\right)$ de 0,012 . Isso reitera o que a inspeção visual mostra:não há variação proporcional entre GA e GI para os atributos de conhecimento. Em outras palavras, um atributo não tem um GI alto porque seu GA é alto, ou um GI baixo porque o seu GA é baixo.Disso decorre que os alunos não aprendem mais sobre os atributos que acham mais importantes para o seu sucesso profissional, nem aprendem menos sobre os atributos que consideram menos importantes. Acredita-se que isso decorra da estratégia adotada pela disciplina, de promover o desenvolvimento do CHA por meio de projetos-piloto. Para a conclusão exitosa dos projetos, os alunos não puderam furtar-se de 
realizar todas as atividades. Essa impossibilidade de seleção do que fazer em função das predileções garantiu a todos a oportunidade do desenvolvimento integral e sistêmico de seus atributos.

A Figura 3, que representa o gráfico GA $x$ GI para as habilidades, aponta um cenário parecido em vários aspectos com o que acabamos de ver para os conhecimentos.

Figura 3: Cruzamento entre os graus de aprendizado e de importância para as Habilidades.

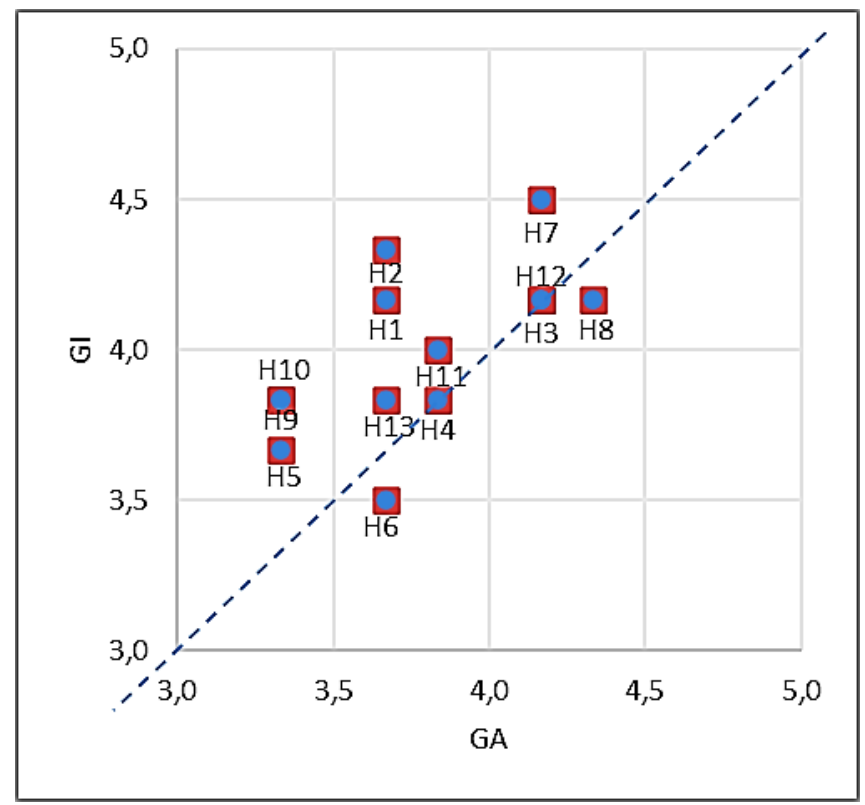

Fonte: Da pesquisa.

Aqui, os GAs se concentram entre 3,3 e 4,3 (média de 3,8), e os GIs ficam entre 3,5 e 4,5 (média de 4,0). Mais uma vez as médias de GA e GI tendem a 4 (apontando para um resultado geral positivo), mas nota-se uma mudança frente aos conhecimentos: há uma diminuiçãona média dos GAs. Essa realidade pode ser vista com o auxílio da linha pontilhada, que indica agora uma concentração de atributos à sua esquerda. Assim, a maioria das habilidades possuem GI superior ao GA. Essa situação é inversa àquela vista na Figura 2, mas não é propriamente uma surpresa, uma vez que a análise dos Quadros 4 e 7 já antecipava essa realidade.

Mais uma vez, a análise de regressão linear apontou um coeficiente de determinação $\left(R^{2}\right)$ de 0,3916 , muito baixo para indicar variação proporcional entre GA e GI.Dessa forma, vemos se repetir a indicação de que não há correlação entre o aprendizado dos alunos e a importância que eles atribuem ao atributo.

Por fim, a Figura 4 mostra o gráfico GA x GI para as atitudes, o qual guarda grande correspondência com a Figura 3. 
Figura 4: Cruzamento entre os graus de aprendizado e de importância para as Atitudes.

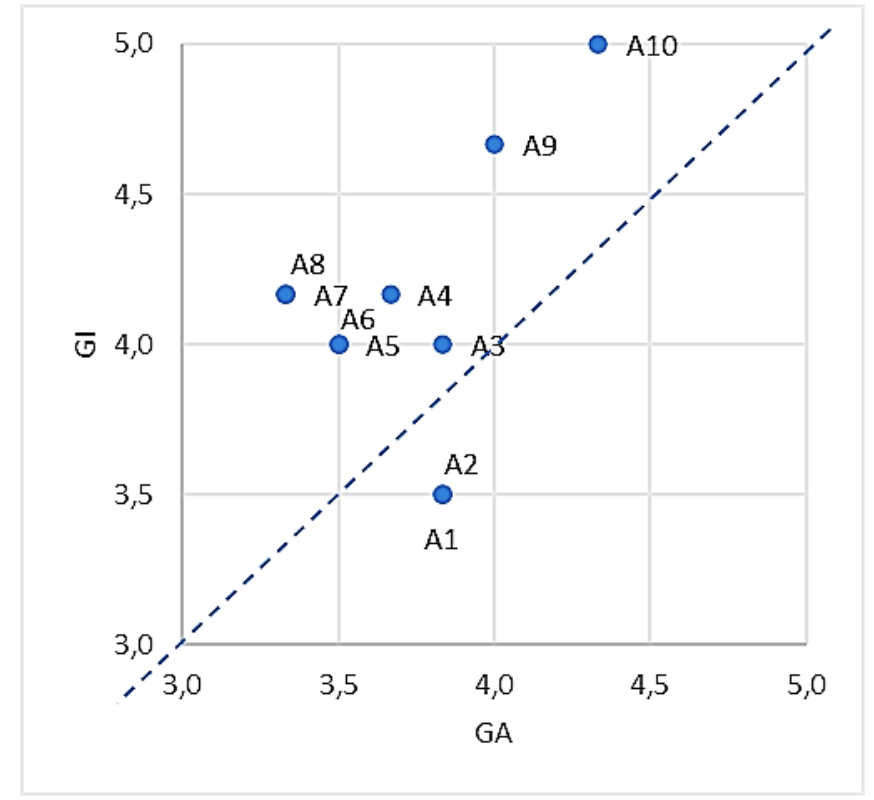

Fonte: Da pesquisa.

Nota-se que os GAs se concentram em sua maioria entre 3,3 e 3,8 (média de 3,7), e que a maior parte dos GIs fica entre 3,5 e 4,2 (média de 4,1). Assim, apesar das atitudes terem a maior média de GI e a menor de GA, novamente as médias tendem a 4 (apontando para um resultado geral positivo). E assim como para as habilidades, há uma concentração de atributos à esquerda da linha pontilhada do gráfico, indicando que a maioria das atitudes possuem GI superior ao GA. Novamente, com a análise de regressão linear e um coeficiente de determinação $\left(R^{2}\right)$ de 0,1812, conclui-se não haver variação proporcional entre GA e GI.

Para encerrar a discussão dos resultados, a título de síntese foi criadooQuadro9, que representa o cruzamento entre os graus de aprendizado e de importância para as três dimensões do CHA. Assim, cada atributo avaliado foi associado a um dos quatro quadrantes do quadro, de modo a revelar visualmente a que combinação entre GA e GI o atributo se encaixa. Os quadrantes foram divididos da seguinte forma:

-Quadrante 1 (graus de importância e de aprendizado altos): figuram nesse quadrante todos os atributos cujos percentuais dos graus de aprendizado e de importância da coluna "(4+5)" sejam, simultaneamente, iguais ou superiores a $50 \%$. Pertence a esse quadrante, por exemplo, a atitude "A10", uma vez que na coluna " $(4+5)$ " do GA relativo a esse atributo aparece o percentual de $83,3 \%$, e na coluna "(4+5)" do GI relativo ao mesmo atributo aparece o percentual de $100 \%$.

- Quadrante 2 (apenas o GI é alto): nesse quadrante entram todos os atributos cujo percentual do GI da coluna "(4+5)" seja igual ou 
superior a 50\%, mas que o mesmo não se aplique à soma dos graus mais elevados de aprendizado. Um exemplo é a habilidade "H10", cuja coluna " $(4+5)$ " do GI relativo ao atributo mostra o percentual de 66,7\%, mas a coluna "(4+5)" do GA relativo ao mesmo atributo não alcança os $50 \%$ (no caso de "H10", o valor é de 33,3\%).

-Quadrante 3 (apenas o GA é alto): idem o item anterior, diferindo apenas pela inversão entre o GI e o GA.

-Quadrante 4 (graus de importância e de aprendizado não-altos): figuram nesse quadrante todos os atributos cujas somas dos graus mais elevados de aprendizado e de importância sejam, simultaneamente, inferiores a $50 \%$.

Quadro9: Cruzamento entre os graus de aprendizado e de importância.

\begin{tabular}{|c|c|c|c|}
\hline & \multicolumn{2}{|c|}{ Grau de Importância (GI) do CHA da disciplina } \\
\hline & & $\begin{array}{l}\text { Todos os atributos com GI alto } \\
\qquad(4+5) \geq 50,0 \%\end{array}$ & $\begin{array}{l}\text { Demais atributos } \\
\qquad(4+5)<50,0 \%\end{array}$ \\
\hline $\begin{array}{c}\text { Grau de } \\
\text { Aprendizado } \\
\text { (GA) do CHA }\end{array}$ & $\begin{array}{l}\text { Todos os atributos } \\
\text { com GA alto } \\
(4+5) \geq 50,0 \%\end{array}$ & $\begin{array}{l}\text { Todas as Atitudes } \\
\text { Todas as Habilidades, exceto H5, H9 e } \\
\text { H10 } \\
\text { Todos os Conhecimentos, exceto C6 }\end{array}$ & --- \\
\hline da disciplina & $\begin{array}{l}\text { Demais atributos } \\
\qquad(4+5)<50,0 \%\end{array}$ & $\begin{array}{c}\mathrm{H} 5, \mathrm{H} 9, \mathrm{H} 10 \\
\mathrm{C} 6\end{array}$ & \\
\hline
\end{tabular}

Fonte: Da pesquisa.

Nota-se pelo quadro que a disciplina foi bem avaliada pelos alunos, uma vez que quase todos os atributos se concentraram no quadrante $1 \mathrm{e}$ os demais, no quadrante 2.0 quadrante 1 representa a posição ideal dos atributos: ter muitos atributos nesse quadrante indica que a disciplina promoveu, para a maioria dos alunos, um aprendizado muito bom ou excelente em vários atributos considerados por eles mesmos como muito importantes ou essenciais para o seu sucesso profissional. Isso representa a melhor combinação entre eficiência (alto aprendizado dos alunos) e efetividade (ótima expectativa de benefício futuro) da disciplina.

\section{Considerações finais}

Esse artigo analisou os resultados de um processo de ensino em IC direcionado a graduandos de Biblioteconomia e Ciência da Informação, no que diz respeito ao aprendizado de certos atributos de competência (i.e., Conhecimentos, Habilidades e Atitudes - $\mathrm{CHA}$ ) e à importância dos mesmos frente ao sucesso profissional idealizado pelos estudantes.Tal análise se baseou na descrição sucinta dos elementos essenciais do 
processo de ensino (uma disciplina optativa de IC de 4 créditos-aula e 2 créditos-trabalho), que lança mão de metodologias ativas para a promoção da integração entre teoria e prática no âmbito da graduação.

Os resultados indicam que a disciplina logrou êxito em várias de suas frentes. No que diz respeito ao aprendizado geral dos alunos, a maioria relata ter alcançado um Grau de Aprendizado (GA) muito bom ou excelente em praticamente todos os atributos de conhecimento. Esse alto GA tem um significado especial quando se trata dos atributos"C8" (O ambiente interno da organização analisada: o que é e seus aspectos principais), "C9" (O ambiente externo da organização analisada: o que é e seus aspectos principais), "C10" (Estratégia formal/oficial da organização analisada) e "C11" (Estratégia informal/real da organização analisada). Como suas descrições já denunciam, esses não são conteúdos ministrados nas aulas, mas sim fruto da própria investigação dos alunos, o que expressa em grande medida o sucesso do uso da metodologia ativa.

Os atributos de conhecimento representam o suporte teórico para a realização das atividades práticas. Uma vez que os resultados de aprendizado dos mesmos foram positivos, a realização dos projetos-piloto e demais atividades práticas ficou facilitada, assim como o desenvolvimento das habilidades e atitudes, uma vez que são justamente os projetos-piloto e as atividades práticas os principais responsá veis pelo desenvolvimento desses atributos.

Mesmo assim, no que tange ao aprendizado das habilidades e atitudes, os resultados revelaram uma maior dificuldade da disciplina em apoiar o desenvolvimento de ambas em comparação com os conhecimentos.Em média os resultados foram bons, mas com ligeiro aumento da presença de avaliações de grau 2 (baixo/insuficiente) e um aumento maior do grau 3 (bom/satisfatório). No caso das atitudes, além desse cenário houve ainda um aumento do grau 4 (muito bom) em função da diminuição do grau 5 (excelente/além das expectativas).

Mesmo com o uso da metodologia ativa e das várias ações de integração teoria-prática, o tempo de assimilação de habilidades ou de mudança de atitudes tende a superar o necessário para a assimilação de conhecimentos. Mesmo assim, a revisão do modo com que as habilidades e as atitudes são trabalhadas na disciplina é salutar e deverá ser realizada.

À análise do GA, a pesquisa agregou a análise do Grau de Importância (GI) dos atributos para o sucesso profissional dos alunos. Nesse quesito, os resultados da disciplina se mostraram muito positivos. Para os atributos de conhecimento, a soma dos GIs mais altos foi dominante e a soma dos GIs na ponta inferior da escala, para a quase totalidade dos atributos, não ultrapassou $16,7 \%$. Situação semelhante foi encontrada quanto à importância das habilidades e atitudes: a não ser por 
"H13" (Extrair, dos resultados da IC, ideias e oportunidades para alavancar o seu próprio sucesso) e "A1" (Motivação/Ímpeto de compreender o ambiente interno da sua organização), todos atributos expressaram baixa soma dos graus inferiores combinada a altas somas dos graus superiores de importância.

Os bons resultados de GA e GI explicam porque a quase totalidade dos atributos ocupa, na Figura 2, o quadrante 1 - no qual aparecem todos os atributos cujos percentuais dos GA e GI da coluna "(4+5)" foram, simultaneamente, iguais ou superiores a $50 \%$. Esse é, em termos de desempenho da disciplina, a melhor situação, uma vez que indica que a disciplina promoveu, para a maioria dos alunos, um aprendizado muito bom ou excelente em vários atributos considerados por eles mesmos como muito importantes para o seu sucesso profissional.

Além da análise geral dos resultados, interessou-nos a reflexão sobre a maneira com que a disciplina, originalmente idealizada para promover o aprendizado dos atributos com enfoque apenas na IC, se comportou no que tange ao sucesso profissional dos alunos. Nesse sentido, fez-se necessária uma análise específica da avaliação do grupo de atributos diretamente conectados a essa questão (i.e., C12, H12, H13, A9 e A10).

No que diz respeito ao GA, os percentuais de $\mathrm{C} 12, \mathrm{H} 12, \mathrm{H} 13, \mathrm{~A} 9$ e A10 na coluna " $(4+5)$ " foram, respectivamente: $83,3 \%, 83,3 \%, 50,0 \%$, $83,3 \%$ e $83,3 \%$. Em suma, a maioria dos alunos acredita ter aprendido muito sobre o significado e a busca do seu sucesso profissional. Quanto à importância desses atributos, os resultados foram 100\%, 66,7\%,50,0\%, $100 \%$ e $100 \%$, evidenciando a percepção de elevada importância dos mesmos pelos alunos. Com isso, pode-se dizer que a disciplina pôde contribuir positivamente quanto ao sucesso profissional dos alunos.

Esse resultado expressivo se deveu em grande parte aos debates em sala de aula e no grupo do Facebook, organizados em função da estratégia profissional (Quadro 1) e do "Roteiro para o Sucesso".Pela descrição dos ciclos de debate e das opiniões pontuais dos alunos,pode-se vislumbrar os efeitos benéficos que essa iniciativa acarretou aos alunos. $\mathrm{Na}$ verdade, para a maioria deles a disciplina propiciou a primeira experiência consistente de reflexão quanto ao significado do sucesso profissional para si, bem como o caminho para atingi-lo. A criação, pela primeira vez na vida de muitos deles, de um plano para a realização do sucesso profissional que eles próprios almejam foi um dos resultados mais relevantes alcançados pela disciplina.

Para além dos êxitos, os resultados desse trabalho também apontaram inúmeras oportunidades de melhoria do processo de ensino adotado. À parte as limitações intrínsecas ao ensino e desenvolvimento de habilidades e atitudes, atributos específicos que carecem de melhorias 
foram identificados. Além disso, revelou-se a importância tanto de se explorar melhor as alternativas de atividades práticas já implementadas, como de se incorporar novas práticas, sobretudo aquelas direcionadas às habilidades e atitudes.

Dado os resultados discutidos e a apresentação, ainda que sumária, da abordagem de ensino, acreditamos na possibilidade de aplicação dessas concepções e ideias a outros cursos de graduação, principalmente os de Biblioteconomia e de Ciência da Informação, haja vista o interesse crescente sobre as alternativas de ensino voltadas ao desenvolvimento das competências dos futuros egressos por meio de metodologias ativas, sobretudo quando essas competências são capazes de dialogar com a busca pelo sucesso profissional dos mesmos.

\section{Referências}

AMARAL, R. M. et al.Modelo para o mapeamento de competências em equipes de inteligência competitiva. Ciência da Informação, Brasília, v. 37, n. 2, p. 7-19, 2008. Disponível em:

https://www.scielo.br/pdf/ci/v37n2/a01v37n2.pdf. Acesso em: 18 set. 2018.

.Perfil de competências relativas à inteligência competitiva: um estudo exploratório no Brasil. Ciência da Informação, Brasília, v. 40, n. 2, p. 125-144, 2011. Disponível em:

http://revista.ibict.br/ciinf/article/view/1306. Acesso em: 22 set. 2018

ARRUDA, M. C. C.; MARTELETO, R. M.; SOUZA, D. B. Educação, trabalho e o delineamento de novos perfis profissionais: o bibliotecário em questão. Ciência da Informação, v. 29, n. 3, p. 14-24,2000. Disponível em: https://www.scielo.br/pdf/ci/v29n3/a02v29n3.pdf. Acesso em: 06 jan. 2019.

BENSOUSSAN, B.; FLEISHER, C. S. Strategic and competitive analysis: methods and techniques for analyzing business competition. Upper Saddle River, NJ: Prentice Hall, 2003.

BEXON, M. ;STEPHENS, D. ;PRITCHETT, C. Competitive intelligence: a career opportunity for the information professional in industry. Journal of Librarianship and Information Science, v. 34, n. 4, p. 187-196, 2002. Disponível em: https://journals-sagepubcom.ez67.periodicos.capes.gov.br/doi/pdf/10.1177/096100060203400402 . Acesso em: 12 nov. 2018.

BLENKHORN, D.;FLEISHER, C. Teaching CI to three diverse groups: undergraduates, MBAs and executives. Competitive Intelligence Magazine, v. 6, n. 4, p. 17-20, 2003. 
CALOF, J.L. Teaching competitive intelligence: opportunities and needs. Competitive Intelligence Magazine, v. 2, n. 4, p. 28-31, 1999.

. Government sponsored competitive intelligence for regional and sectoral economic development: Canadian experiences. Journal of Intelligence Studies in Business, v. 6, n. 1, p. 48-58,2016. Disponível em: https://ojs.hh.se/index.php/JISIB/article/viewFile/153/pdf. Acesso em: 13 dez. 2018.

DUTRA, J. S. Gestão de carreiras: a pessoa, a organização e as oportunidades. 2. ed.São Paulo: Atlas, 2019.

DUTRA, T. N. A.; CARVALHO, A. V. O profissional da informação e as habilidades exigidas pelo mercado de trabalho emergente. Encontros Bibli: Revista Eletrônica de Biblioteconomia e Ciência da Informação, v. 11, n. 22, p. 178-194, 2006. Disponível em: https://periodicos.ufsc.br/index.php/eb/article/download/15182924.2006v11n22p178/437. Acesso em: 12 jan. 2019.

FARIA, S. et al. Competências do profissional da informação: uma reflexão a partir da Classificação Brasileira de Ocupações. Ciência da Informação, v. 34, n. 2, p. 26-33, 2005. Disponível em:

http://revista.ibict.br/ciinf/article/download/1087/1192. Acesso em: 05 dez. 2018.

FERREIRA, D. T. Profissional da informação: perfil de habilidades demandadas pelo mercado de trabalho. Ciência da Informação, v. 32, n. 1, p. 42-49, 2003. Disponível em:

https://www.scielo.br/pdf/ci/v32n1/15972.pdf. Acesso em: 03 dez. 2018.

FLEISHER, C.S. Competitive intelligence education: competencies, sources and trends. Information Management Journal, v. 38, n. 2, p. 56-62, 2004.Disponível em: https://link.gale.com/apps/doc/A114475667/AONE?u=usp br\&sid=AONE \&xid=8c66db05. Acesso em: 25 out. 2018.

FULD, L. M. The new competitor intelligence: the complete resource for finding, analyzing and using information about your competitors. New York: John Wiley \& Sons, 1995.

GARCIA, L. G. Inteligência competitiva com enfoque empreendedor: ensino e pesquisa na graduação em ciência da informação. In CID: Revista de Ciência da Informação e Documentação, v. 2, n. 2, p. 111-124, 2011. Disponível em: 
http://www. revistas.usp.br/incid/article/view/42355/46026. Acesso em: 25 set. 2018.

. Roteiros de desenvolvimento de unidades de inteligência competitiva sob a ótica dos modelos de referência. Encontros Bibli: Revista Eletrônica de Biblioteconomia e Ciência da Informação, v. 18, n. 38, p. 65-86, 2013. Disponível em: https://periodicos.ufsc.br/index.php/eb/article/view/15182924.2013v18n38p65/25957. Acesso em: 17 out. 2018.

GIL, A. C. Como elaborar projetos de pesquisa. 4 ed. São Paulo: Atlas, 2007.

GILAD, B. CI education harvard style? Competitive Intelligence Magazine, v. 6 , n. 4, p. 12-16, 2003.

GREINER, L. E.; BHAMBRI, A.; CUMMINGS, T. G. Searching for a strategy to teach strategy. Academy of Management Learning and Education, v. 2, n. 4, p. 402-420, 2003. Disponível em:

https://journals.aom.org/doi/full/10.5465/amle.2003.11902092. Acesso em: 22 nov. 2018.

GUIMARÃES, J. A. C. Moderno profissional da informação: elementos para sua formação no Brasil. Transinformação, Campinas, v.9, n.1, p.124-137, 1997. Disponível em: http://periodicos.puccampinas.edu.br/seer/index.php/transinfo/article/view/1597/1569. Acesso em: 15 jan. 2019.

GUTOWSKI, N. Competitive intelligence education: the problem begins in high school. Competitive Intelligence Magazine, v. 10, n. 3, p. 42-43, 2007.

KAHANER, L. Competitive intelligence: how to gather, analyze and use information to move your business to the top. New York, NY: Touchstone, 1996.

KALB, C.C. Core competencies: a practioner's view. Competitive Intelligence Magazine, v. 6, n. 4, p. 53-55, 2003.

LEMMER, C.A. Using competitive intelligence instruction to develop practice-ready legal professionals. Legal Reference Services Quarterly, v. 34, n. 4, p. 268-292, 2015. Disponível em: https://www.tandfonline.com/doi/full/10.1080/0270319X.2015.1102024. Acesso em: 09 dez. 2018. 
LINTON, D. L. et al. Identifying key features of effective active learning: the effects of writing and peer discussion. Life Sciences Education, v. 13, n. 3, p. 469-477, 2014. Disponível em:

https://www.lifescied.org/doi/full/10.1187/cbe.13-12-0242. Acesso em: 06 out. 2018.

MARCIAL, E. C. Proposta inicial de uma teoria geral da inteligência competitiva. Ciência da Informação, v. 45, n. 3, p. 59-75, 2016.

Disponível em: http://revista.ibict.br/ciinf/artide/view/4048/3566. Acesso em: 07 set. 2018.

McGONAGLE, J.J. Training betteranalysts. Competitive Intelligence Magazine, v. 10, n. 6, p. 51-52, 2007.

MILLER, J.P. Educational programs for intelligence professionals. Library Trends, v. 43, n. 2, p. 253-270, 1994. Disponível em:

https://www.ideals.illinois.edu/bitstream/handle/2142/7956/librarytrends v43i2h opt.pdf?sequence. Acesso em: 20 nov. 2018.

OLIVEIRA, P.; LACERDA, J. Habilidades e competências desejáveis aos profissionais de inteligência competitiva. Ciência da Informação, v. 36, n. 2, p. 46-53, 2007. Disponível em:

https://www.scielo.br/pdf/ci/v36n2/05.pdf. Acesso em: 25 set. 2018.

QUEYRAS, J.; QUONIAM, L. Inteligência competitiva. In: TARAPANOFF, K. (Org.) Inteligência, informação e conhecimento em corporações. Brasília: IBICT, UNESCO, 2006.

RICHARTZ, T. Metodologia ativa: a importância da pesquisa na formação de professores. Revista da Universidade Vale do Rio Verde, Três Corações, v. 13, n. 1, p. 296-304, 2015. Disponível em:

http://periodicos.unincor.br/index.php/revistaunincor/article/view/2422/p df 308. Acesso em: 27 out. 2018.

RUIZ-PRIMO, M. A. et al. Impact of undergraduate science course innovations on learning. Science, v. 331, n. 6022, p. 1269-1270, 2011. Disponível em:

https://science.sciencemag.org/content/331/6022/1269.full. Acessoem: 22 jan. 2019.

RUNTUWENE, J.P.A.;KENAP, A.A. ;PALILINGAN, V.R. The development of north Sulawesi through competitive intelligence. Journal of Intelligence Studies in Business, v. 4, n. 1, p. 36-42, 2014.Disponível em: https://ojs.hh.se/index.php/JISIB/article/view/85/84. Acesso em: 10 out. 2018. 
SODERDAHL, P. A. Library classroom renovated as an active learning classroom. Library Hi Tech, v. 29, n. 1, p. 83-90, 2011. Disponível em: https://www.emerald.com/insight/content/doi/10.1108/07378831111116 921/full/html. Acesso em: 01 nov. 2018.

THIOLLENT, M. Metodologia da pesquisa-ação. 17. ed. São Paulo: Cortez, 2009.

TARAPANOFF, K. Informação, conhecimento e inteligência em corporações: relações e complementaridade. In: TARAPANOFF, K. (Org.) Inteligência, informação e conhecimento em corporações. Brasília: IBICT, UNESCO, 2006.

TYSON, K. W. M. The complete guide to competitive intelligence. 5. ed. Englewood Cliffs, NJ: Prentice Hall, 2010.

VALENTIM, M. L. O moderno profissional da informação: formação e perspectiva profissional. Encontros Bibli: Revista Eletrônica de Biblioteconomia e Ciência da Informação, v.5, n.9, p.16-28, 2000. Disponível em: https://periodicos.ufsc.br/index.php/eb/article/view/15182924.2000v5n9p16/5058. Acesso em: 28 set. 2018.

ZARIFIAN, P. Objetivo competência: por uma nova lógica. São Paulo: Atlas, 2001.

ZHOU, Y.; WANG, Z. The training strategy of professional core competencies of talents in competitive intelligence. Research Journal of Applied Sciences, Engineering and Technology, v. 5, n. 16, p. 4088-4093, 2013. Disponível em:

https://maxwellsci.com/msproof.php?doi=rjaset.5.4630. Acesso em: 07 nov. 2018. 